University of Louisville

ThinkIR: The University of Louisville's Institutional Repository

Electronic Theses and Dissertations

$5-2021$

\title{
A case study in the use of mentorships in academic instructional coach development.
}

\author{
Matt Anderson \\ University of Louisville
}

Follow this and additional works at: https://ir.library.louisville.edu/etd

Part of the Educational Assessment, Evaluation, and Research Commons, Educational Leadership Commons, Elementary and Middle and Secondary Education Administration Commons, Elementary Education Commons, Elementary Education and Teaching Commons, Junior High, Intermediate, Middle School Education and Teaching Commons, Other Educational Administration and Supervision Commons, Other Teacher Education and Professional Development Commons, Secondary Education Commons, Secondary Education and Teaching Commons, Social and Philosophical Foundations of Education Commons, and the Urban Education Commons

\section{Recommended Citation}

Anderson, Matt, "A case study in the use of mentorships in academic instructional coach development." (2021). Electronic Theses and Dissertations. Paper 3607.

https://doi.org/10.18297/etd/3607

This Doctoral Dissertation is brought to you for free and open access by ThinkIR: The University of Louisville's Institutional Repository. It has been accepted for inclusion in Electronic Theses and Dissertations by an authorized administrator of ThinkIR: The University of Louisville's Institutional Repository. This title appears here courtesy of the author, who has retained all other copyrights. For more information, please contact thinkir@louisville.edu. 


\title{
A CASE STUDY IN THE USE OF MENTORSHIPS IN ACADEMIC INSTRUCTIONAL COACH DEVELOPMENT
}

\author{
By \\ Matt Anderson \\ B.A., Purdue University, 2006 \\ M.A., University of Louisville, 2007 \\ Dissertation \\ Submitted to the Faculty of \\ The College of Educational and Human Development of \\ The University of Louisville \\ in Partial Fulfillment of the Requirements \\ for the Degree of
}

Doctor of Education in Educational Leadership and Organizational Development

Department of Educational Leadership, Evaluation, and Organizational Development University of Louisville

Louisville, Kentucky

May 2021 
Copyright 2021 by Matthew Anderson

All rights reserved 



\title{
A CASE STUDY IN THE USE OF MENTORSHIPS IN ACADEMIC INSTRUCTIONAL COACH DEVELOPMENT
}

\author{
By \\ Matt Anderson \\ B.A., Purdue University, 2006 \\ M.A., University of Louisville, 2007 \\ A Dissertation
}

March 30, 2021

By the following Dissertation Committee

W. Kyle Ingle

Professor Directing Dissertation

Katy DeFerrari

Marco Munoz

Harrie Buecker 


\section{DEDICATION}

This dissertation is dedicated to Ruby and Maxwell. May you both realize your

unlimited potential and understand your ability to accomplish anything. Always encourage each other to do so. 


\section{ACKNOWLEDGEMENTS}

I would like to thank my wife, Meagan; my mother, Sue Anderson; and the rest of my family for their patience and support throughout this process. A special thanks also goes to my committee members: Dr. W. Kyle Ingle (Chair), Dr. Katy DeFerrari, Dr. Marco Munoz, and Dr. Harrie Buecker. I am also grateful for those that inspired, encouraged, and challenged me along the way: Dr. Molly Sullivan, Dr. Bradley Carpenter, Dr. Namok Choi, Dr. Tiffanie Lewis-Durham, Dr. David Anderson, Dr. Kara Ammerman, Julie Chancellor, Kevin the RV, Waggener High School students and staff, University of Louisville ELEOD classmates, and JCPS colleagues I have worked with on this journey. 


\title{
ABSTRACT \\ A CASE STUDY IN THE USE OF MENTORSHIPS IN ACADEMIC INSTRUCTIONAL COACH DEVELOPMENT
}

\author{
Matthew Anderson
}

March 30, 2021

Academic instructional coaches have long been used to support teacher development and student learning. As a recent position in the education field, there is little information regarding the development of staff in this role. This study sought to better understand how academic instructional coaches are mentored and developed within challenging school contexts. The theoretical framework for this research is guided by the social constructivism epistemology. In alignment with this framework, a collective case study was utilized to better understand the relationship between the principal and the academic instructional coach. Exploring this relationship emphasized how principals support academic instructional coach growth. Findings highlight the importance of academic instructional coach and principal relationships in forming clear opportunities to have honest dialogue and foster feelings of support. The research shows there is an overall lack of systems to support coaches and develop necessary relationships although coaches desire and seek out these opportunities. The Accelerated Improvement School context presented numerous challenges for principals and coaches. However, this particular context does offer some benefits including an atmosphere of collegiality, team support, and friendship that propagated relationships. 


\section{TABLE OF CONTENTS}

DEDICATION

ACKNOWLEDGEMENTS

ABSTRACT $\quad$ V

LIST OF TABLES Viii

LIST OF FIGURES $\quad$ ix

CHAPTER I: INTRODUCTION 1

Purpose of the Study 3

Research Questions

Definition of Terms $\quad 6$

$\begin{array}{ll}\text { Organization of the Study } & 7\end{array}$

CHAPTER II: LITERATURE REVIEW 8

Defining Mentoring 9

Mentoring in Education $\quad 11$

Benefits of Mentorships for Teachers and School Leaders $\quad 15$

$\begin{array}{ll}\text { Academic Instructional Coaching } & 18\end{array}$

Roles and Benefits of Academic Instructional Coaching 19

Training Academic Instructional Coaches 25

Theoretical Underpinnings of Coaching Mentors 28

CHAPTER III: METHODOLOGY 33

The Purpose and Research Questions 34

Context of the Study 34

Participants and Sampling $\quad 36$

Strategy of Inquiry $\quad 40$

Data Collection Procedures $\quad 41$

Data Analysis $\quad 43$

Strategies for Ensuring Credibility, Transferability, Dependability, and Confirmability 44 
Researcher Positionality $\quad 45$

CHAPTER IV: RESULTS 46

The Development of Academic Instructional coaches in AIS School Contexts 46

Mentorship According to Principals 47

Mentorship According to Academic Instructional Coaches 53

Cross-Case Analysis: The Development of Mentorship According to both Academic

Instructional Coaches and Principals $\quad 58$

The Provision of Mentoring Supports and their Perceptions of Benefits 66

Mentoring Supports and their Perceptions of Benefits according to Principals 66

Mentoring Supports and their Perceptions of Benefits According to Coaches 69

Cross-Case Analysis: The Provision of Mentoring Supports and their Perceptions of

Benefits According to both Principals and Coaches $\quad 71$

Mentorship in the AIS context $\quad 75$

CHAPTER V: DISCUSSION AND IMPLICATIONS 79

Implications for Policy $\quad 84$

Implications for Practice $\quad 86$

Implications for Future Research $\quad 89$

REFERENCES $\quad 91$

APPENDIX A: INFORMED CONSENT 98

APPENDIX B: INTERVIEW PROTOCOL (COACH) 102

APPENDIX C: INTERVIEW PROTOCOL (PRINCIPAL) 104

CURRICULUM VITAE 106 


\section{LIST OF TABLES}

Table 1. Principal Participants and School Demographics ......................................... 39

Table 2. AIC Participants and school demographics........................................... 40

Table 3. Principal's mentoring practices themes and codes ................................ 48

Table 4. Principal's mentoring practices themes and codes .................................. 54

Table 5. Provision of Mentoring Supports and their Perceptions of Benefits According to

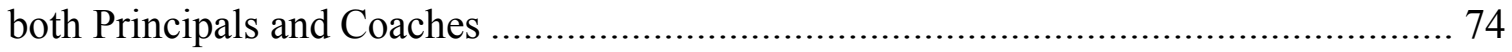




\section{LIST OF FIGURES}

Figure 1. Conceptual Framework ............................................................................. 30 


\section{CHAPTER I: INTRODUCTION}

As education accountability pressures continue to mount, districts and schools are looking to implement many new strategies and programs designed to boost student achievement and address student learning needs (Newstead, Saxton, \& Colby, 2008; Skedsmo \& Huber, 2019). Pressures to meet recent school accountability requirements have been accompanied by significant levels of funding from a variety of state and federal sources (Denton \& Hasbrouck, 2009). This money works to fund many new education initiatives such as changes in curriculum, increased assessment, and the hiring of additional support personnel such as academic instructional coaches. While the rationale behind many of these programs is strong and supported by research, many initiatives are developed and implemented with little oversight, strategic planning, and lack a blueprint for evaluating effectiveness (Stock \& Duncan, 2010). One trending strategy currently being used at the state and district level has been to hire additional personnel, known as academic instructional coaches (Deussen, 2007; Marsh, McCombs, \& Martorell, 2012; Stock \& Duncan, 2010). Academic instructional coaches are hired at the state, district, and school level and work within schools to aide accountability efforts by supporting teachers, analyzing student learning data, and leading school-level initiatives (Deussen, 2007; Marsh et al., 2012; Stock \& Duncan, 2010). Not surprisingly, the placement of these academic instructional coaches provide additional supports in schools or districts identified as persistently low achieving. Although these positions 
seek to support teachers in the implementation of state-level curriculum and school-level initiatives, academic instructional coaches also participate in a wide range of activities at the school level (Center for Collaborative Education, 2002; Denton \& Hasbrouck, 2009; Deussen, 2007; Washburn-Moses, 2010). In fact, across the nation, a brief review of academic instructional coach positions reveals large variations in job titles, job descriptions, and varying evaluation methods (Center for Collaborative Education, 2001; Denton \& Hasbrouck, 2009). Much of this has led to ambiguity around the academic instructional coaching position as a whole.

Schools rely heavily on academic instructional coaches to help improve instruction and various classroom related functions. However, academic instructional coaches do not receive training on how to carry out this wide range of tasks effectively. Academic instructional coaches are considered multi-tools, requiring a broad range of skills used to mentor new teachers, lead professional development, and monitor student learning (CCE, 2001). Many academic instructional coaches rely on their experience as classroom teachers to develop these skills (Coggins, Stoddard, \& Culter, 2003). Often, the skill sets required for a coaching position are quite different from the skills needed as a teacher. Therefore, coupled with high levels of inexperience, academic instructional coaches often feel ill equipped to support teachers in the coaching process (Deussen, 2007; Stock \& Duncan, 2010). As teachers move into these academic instructional coaching positions, they typically receive limited formal training (Deussen, 2007; Stock \& Duncan, 2010). If academic instructional coaches are not being trained or supported to develop these skills, questions arise as to they how can effectively support student achievement? 
In an effort to impact the struggling school setting where most of these positions are placed positively, academic instructional coaches need professional development to address the specific needs of a school in need. More research in this area will serve to improve the role of the academic instructional coach position in these types of settings. Given the menial formal training available and clear need for support, academic instructional coaches look for support on their own. Often this means learning from other administrators or looking to more experienced coaches in similar roles (CCE, 2002). As with the development of teachers and administrators, academic instructional coaches may also attempt to develop appropriate skills through mentorships. Therefore, with an emphasis on mentorship, the proposed research will work to identify the specific ways academic instructional coaches develop through mentoring in persistently low-achieving schools.

\section{Purpose of the Study}

Mentoring and academic instructional coaching literature will be utilized to frame and understand this problem. The mentorship literature is relevant, as mentorship is a way in which leaders develop (Copeland \& Calhoun, 2004; Washington, 2007). For example, mentoring has been utilized to develop personnel in a variety of fields including education, business, and medicine (Copeland \& Calhoun, 2004; Washington, 2007). Specific to education, mentorship is a means of developing teacher interns, new teachers, and school administrators (Copeland \& Calhoun, 2014; Fletcher, 2012; Lee Hean, 2005; Washington, 2007). For the purposes of this research study, mentoring is defined as a relationship of ongoing support, collaboration, and the development of knowledge and skills that translate into improved teaching strategies (Cook, 2012). The literature for this 
study will delve deeper in to this topic by providing a rationale for mentoring as a staff development tool. It will also address the specific ways mentorship cultivates teachers and administrators in education. As similar educational role groups working in similar contexts, a clear understanding of teacher and administrator mentoring may frame the development of academic instructional coaching mentorships, where little research currently exists. At present, the mentorship literature reveals the use of mentoring as a development strategy for pre-service teachers, in-service teachers, and for teachers and administrators in becoming school leaders. In the literature, mentorship, used as a development opportunity, provides many benefits to teachers and administrators. Many of these benefits include improved staff retention and teacher quality (Saffold, 2006; Washburn-Moses, 2010). However, little research exist that examines how academic instructional coaches, or other education positions, may or may not be utilizing mentorships for their development. This could be detrimental to the academic instructional coach position rationale, as many of these coaches indicate a strong desire for additional support and training (Marsh, McCombs, \& Martorell, 2012). More research in this area could help determine the extent to which (and how) coaches use mentorships to address critical needs.

Of similar importance, the academic instructional coaching literature will inform this study of the academic instructional coaching position. This includes understanding the specific roles academic instructional coaches have in schools and varying contexts around the nation. This literature will explain the characteristics of persons who become academic instructional coaches and the widespread duties academic instructional coaches perform (CCE, 2001; Duesson, 2007; Guinney, 2001). Most importantly, the academic 
instructional coaching literature will highlight numerous gaps in understanding how academic instructional coaches are developed. This includes the limited support these coaches receive, the areas in which they struggle, and the lack of understanding of the role in the context of Accelerated Improvement Schools (AIS) schools (Stock 2013).

Ultimately, more research will inform our understanding of the mentoring of academic instructional coaches in these contexts. Such research could have significant implications for policy, practice, and future research. At the policy level, research in this area may inform the effective and efficient implementation of academic instructional coaching (CCE, 2001). From a practitioner's standpoint, the findings from this research could work to enhance support and development systems for academic instructional coaches. This could lead to improvements in teacher retention and student outcomes. This study has additional implications for district administrators and school principals interested in developing capacity within the academic instructional coaching role. Particularly, understanding the role school leaders have in mentoring and developing their academic instructional coaches can create more opportunities for coach development.

\section{Research Questions}

Given the limited research on how to improve the development of academic instructional coaches, the purpose of this qualitative case study is to understand the role between mentorship and academic instructional coaches in an U.S. urban school district. The following research questions guided the development, design, and delivery of this study: 
1) How are academic instructional coaches developed and mentored in an AIS school context?

2) What mentoring supports do academic instructional coaches perceive as beneficial to their development?

\section{Definition of Terms}

As the literature will highlight, various terms exist to define mentorship and education. However, the following terms are used in the context of this study:

Academic instructional coaches - "Academic instructional coaching is a way to support teachers in their efforts to provide high quality teaching in academic areas including reading, math, and science. In many applications, it is also a component in school change initiatives" (Denton \& Hasbrouck, 2009, p.151).

Accelerated Improvement School (AIS) - As defined by the state in which these schools operate, an Accelerated Improvement School has consistently failed to meet the targeted accountability benchmark outlined by the state for consecutive years. Additionally, each of these schools receives differentiated support from district staff and assistant superintendents. These schools are given special emphasis, support, and attention when the district makes decisions and assigns resources in order to foster success. Mentoring - Cook (2010) and Halai's (2006) definitions of mentoring paint the most accurate depiction of mentoring for this study. According to Cook (2010), mentoring is defined as a relationship of ongoing support, collaboration, and the development of knowledge and skills that translate into improved teaching strategies. Halai (2006) strengthens this definition by describing the mentorships as a relationship in which both the mentor and mentee experience growth. 


\section{Organization of the Study}

Chapter I includes the introduction, purpose, research questions, definition of terms, and a description of the organizational structure of the study. Chapter II reviews the existing literature related to mentoring and academic instructional coaches. Chapter III explains the research methodology used in the context of this study. Chapter IV is a presentation of the findings from that analysis and a discussion of the results of the study. Chapter V concludes the study with a summary of major findings and implications of these findings for policy, practice, and future research. 


\section{CHAPTER II: LITERATURE REVIEW}

The extant research literature will serve to frame the context and provide a guide for understanding mentoring, academic instructional coaching, and academic instructional coaching development. First, the history, definition, and implications for mentorship will be reviewed. Building on this foundation, the literature on mentoring in education will be outlined. Specifically, this research will provide relevance by attempting to situate mentoring within the realm of education. In doing so, most of the research on mentoring in education will be discussed as it relates to pre- and in-service teachers and school leaders and administrators. This is due largely in part to the limited research on the mentoring of academic instructional coaches. However, this literature is both relevant and necessary for establishing background relevant to the understanding of academic instructional coach mentoring.

Once a clear picture of mentoring in the educational context is presented, literature around the role of academic instructional coaching will be presented. This literature will explicitly define and explain the role of the academic instructional coach within a modern context. The presented academic instructional coaching literature will also frame the development of the academic instructional coaching position in the United States and identify the specific people who become academic instructional coaches.

Alongside a list of benefits of both mentoring and academic instructional coaching, the literature review will conclude with an identification of current gaps in 
academic instructional coaching mentoring and suggested areas of research. The literature on academic instructional coaching will highlight there is an intense need for academic instructional coaching development as suggested by current coaches.

Currently, little knowledge exists explaining how academic instructional coaches are actually getting and receiving support to work in AIS school contexts. Given the lack of formal training and support available to academic instructional coaches, the literature on mentoring proposes academic instructional coaches may be able to seek support and development from administrators and other experienced coaches effectively. As current administrators and developing teachers utilize mentorships as an opportunity to grow and development, it may be that academic instructional coaches are doing so as well. This research will seek to understand the mentoring of academic instructional coaches and the strategies beneficial to their development and practice.

\section{Defining Mentoring}

As a development strategy widely used in business, medicine, and educational contexts, mentoring has long been a meaningful way for professionals to learn and gain knowledge (Copeland \& Calhoun, 2014; Fletcher, 2012; Lee Hean, 2005; Washington, 2007). Long before its mention in the educational context, the idea of mentoring was evident in Greek mythology (Lee Hean, 2005; Russell \& Russell, 2011). In The Odyssey, King Ulysses entrusted his child's development to Telemachus (Lee Hean, 2005; Wilson, 2001). The child's development was to include such things as education, physical improvement, and occupational development (Wilson, 2001). Although mentoring has continued throughout history, researchers did not formally recognize it until the 1980s and 1990s (Chao, 1992). During this time, much of the introductory work on mentoring 
was developed by Kram (1983). According to Kram (1985), mentoring is a developmental relationship centering on career development and guidance developing out of a need for support. In addition, Kram (1983) explains mentorship arises out of a new employee's search for positive social relationships and solutions to career issues. Through the interaction between the mentor and employee, a "mentor relationship" is created (Kram, 1983, p. 617). Kram (1983) argues both the mentor and protégé can experience psychological and career development benefits.

Kram (1983) says the mentor relationship develops over five phases. The first phase, initiation, describes a period of time in which the mentor and protégé develop some level of relationship. In the second, cultivation phase, the two continue to foster a relationship and begin to connect at an emotional level. It is during this phase the mentor begins to provide social and career development advice. The separation phase, describes the process through which the relationship begins to disintegrate based on structural changes within an organization or changes of individual needs. Lastly, the redefinition phase, describes a period of time in which the relationship ends or is modified to a peerto-peer, rather than mentor to protégé, relationship. Building on the works of Kram, Chao (1992), set out to differentiate the two types of mentoring that occur in organizations. Chao (1992) explains:

The basic distinction between formal and informal mentorships lies in the formation of the relationship. Informal mentorships are not managed, structured, nor formally recognized by the organization. In contrast, formal mentorships are programs managed and sanctioned by the organization. (p. 62) 
This differentiation highlights the two ways mentoring relationships form. Essentially, participants self-select mentors or the organization's leaders assign them via a formalized process.

Though this early work focused solely on mentorships in organizations containing business managers, mentoring has since taken many different meanings and infiltrated many different contexts including education, the health industry, and even female leadership (Copeland \& Calhoun, 2014; Fletcher, 2012; Lee Hean, 2005; Washington, 2007). While the general definition and function of mentoring is similar amongst these professions, many different mentorship models exist (Ehrich, Hansford, \& Tennet, 2004). For these reasons, the mentorship literature is not only vast, but also specific to each profession. Therefore, for the purpose of brevity, the literature presented below focuses solely on mentoring in the education field.

\section{Mentoring in Education}

Within education alone, mentoring models exist for special education, technology, student teaching, new teachers, and school principals (Cook, 2012; Graves, Abbitt, Klett, \& Wang, 2009; Hellsten, Prytula, Ebanks, \& Lai, 2009; Hudson, 2010; Stanulis \& Ames, 2009; Washburn-Moses, 2010). While many general definitions of mentoring in education exist (Halai, 2006), Cook (2012) describes mentoring as the following: "Mentoring is to foster a relationship of ongoing support, collaboration, and the development of knowledge and skills that translate into improved teaching strategies" ( $\mathrm{p}$. 3). To improve this teaching, He (2010) explains the teacher will receive support in the areas of content and pedagogy. Similar to Kram (1983), Halai (2006) extends the 
educational mentor definition to include the development of a nurturing relationship beneficial to both the mentor and the mentee.

As mentioned previously, many education models exist about how one effectively mentors, and many models are designed solely for the area of education in which they were created (Hellsten et al., 2009). For example, Graves et al. (2009) attempted to develop an online mentoring program to support the implementation of a new technology system. Other models include the development of a mentorship system for teachers of special education (Washburn-Moses, 2010) and the mentoring of pre-service teachers (Hudson, 2010). One model applicable to both in-service teachers and pre-service teachers was researched by Hudson (2010). This model contains five components and proven reliable by empirical evidence (Hudson, 2010). Attempting to replicate previous findings for the mentoring of pre-service math teachers, Hudson (2010) used surveys of 147 teachers to understand how they perceive mentoring as it related to the development of the teaching of science. The significant findings of the study indicated a strong correlation between the five factors of the model and key practices of mentoring experienced by the participants. The first component of the model describes the "personal attributes" of the mentee. This includes a supportive nature, the development of trust, and instilling confidence in the mentee. Another key component of the model is the "system requirement" which occurs when the mentor outlines the particular guidelines utilized in the mentoring process. This includes an overall understanding of teaching goals determined by state specified curricula and requirements. Third, in the "pedagogical knowledge" component, the mentor describes the key factors leading to improved teaching. This includes proper lesson planning, content development, and 
identification of resources. In "modeling", the fourth component, Hudson (2010) describes the role of the mentor in providing the pedagogical knowledge mentioned above by modeling appropriate teachings. Lastly, the $5^{\text {th }}$ component, "feedback component", provides the mentor an opportunity to provide feedback around the originally outlined goals. This model is also in alignment with the general definition of educational mentoring mentioned above and provides a substantial overview of the specific ways mentoring is implemented in education.

Education mentoring programs have traditionally served two groups - teachers and educational leaders. Mentorships serve to develop and retain novice teachers. Most of this research highlights the characteristics of quality mentor teachers and the specific ways mentors are utilized in education. For example, Hellsten et al. (2009) studied the implementation of a new teacher mentorship in an effort to understand key components of mentorships. The findings of this study indicated that mentors serve a variety of roles to support teachers. This includes the emotional support that can be found in more informal mentorships and professional support found in supporting teachers develop instructionally (Hellsten et al., 2009) In a similar analysis of a mentorships, conducted by Hudson (2010), researchers attempted to understand additional ways mentors support teachers. Utilizing surveys and structured questionnaires, the researchers questioned 72 mentors. Hudson's analysis revealed primary school mentors spend a majority of their time working with new teachers to support math instruction. In a similar vein, using an exploratory case study design, Saffold (2006) studied 15 new teachers in an urban context to answer the following question: How does mentoring positively influence teacher retention? The participants emphasized the importance of mentoring in building self- 
confidence in teachers, developing competence in a beginning teacher's ability to teach, and engaging with collegial networks in support of teaching. Each of these studies emphasizes the idea that mentorship programs support novice teachers in their personal and professional development.

Although most research on how teachers are mentored occurs with novice teachers, there is limited research describing how mentors are used to support experienced teachers as they work to implement a new curriculum or program. One isolated example involves a case study of one experienced teacher who was mentored by two university professors in an attempt to implement a new curriculum (Shulman, 2004). Using interviews and observations, Shulman found mentors are often able to motivate a teacher to change and implement a new program. The aforementioned studies are just several examples of the numerous ways mentorships support both novice and experienced teachers. According to these studies, mentors provide teachers professional support guided to improving instruction and retaining teachers. Most importantly, these studies indicate that most mentoring occurs with novice teachers.

Other mentorship programs focus on the development of veteran teachers in becoming school administrators. Aside from new teacher mentoring, administrative development mentoring represents another major form of mentorships (Browne-Ferrigno, 2007; Copeland \& Calhoun, 2014; Normore, 2007; Versland, 2013). Specifically, many of these mentorships focus on developing and recruiting teachers to become assistant principals, principals, and superintendents (Augustine-Shaw \& Funk, 2013; BrowneFerrigno, 2007; Normore, 2007). 
While most educational leadership mentoring programs exist to develop leaders, other programs are designed to recruit and retain leaders. These mentorship programs are also typically located in rural and urban areas due to a constant need for employees at the administrative level (Normore, 2007; Versland, 2013). Such programs seek to develop capacity within strong school-level leaders utilizing professional development and handson experience (Normore, 2007). For example, Normore (2007) emphasized a need for strong leadership candidates in urban contexts. The results of the study indicated the leadership programs containing mentorships led to an ample number of qualified candidates for leadership positions. In an effort to understand how to recruit and retain leaders in rural contexts, Versland (2013) interviewed three principals who had experienced a loss of self-efficacy during the initial stages of their careers. According to Versland (2013), this loss of self-efficacy had led many principals to leave the profession. Participants explained their leadership self-efficacy was diminished due to a lack of prior leadership experiences, the leader selection processes, and the leaders relationships with others influential leaders. As a result, Versland (2013) suggested mentoring as one strategy for effective leadership development and retention in rural schools.

\section{Benefits of Mentorships for Teachers and School Leaders}

Given the nature of mentoring, one might argue mentoring has positive benefits for aspiring teachers and school leaders. In fact, both teacher mentoring and leadership development literature support this idea. A meta-analysis of mentoring research conducted by Ehrich et al. (2004) discovered 47.8 percent of mentors and 82.4 percent of mentees in all studies analyzed, experienced positive benefits as a result of the mentoring process. Some of these benefits include both academic and social gains. Specifically, 
those participating in the mentoring process expressed personal satisfaction, collegiality, and reflection (Ehrich et al., 2004; Iancu-Haddad \& Oplatka, 2009). Other gains include teacher retention and increased teacher quality (Saffold, 2006; Washburn-Moses, 2010).

In the mentoring literature, the development of assistant principals, principals, and superindentents fall under the overarching umbrella of leadership development (Augustine-Shaw \& Funk, 2013; Browne-Ferrigno, 2003; Normore, 2007). While only a portion of this literature discusses mentorships, it does highlight some additional benefits of mentoring. Generally, research in this area centers around the evaluation of leadership preparation programs encompassing leadership development. Many of these studies also stress the importance of mentoring in leadership development. For example, a study was conducted by Normore (2007) regarding the implementation of four leadership development programs for aspiring leaders and current educatinal leaders. Using semistructured interviews, researchers asked program participants and district personnel to evaluate the effectiveness of the above preparation programs. Among other things, participants stated mentoring is one of the most beneficial aspects of their personal leadership development. Similar findings were discovered in a study on superintendant development conducted by Augustine-Shaw and Funk (2013). In the evaluation of the Kansas Educational Leadership Institute designed to support new leaders across the state, interviews of both new and veteran superintendents revealed participants valued face-toface mentoring as having a signficant effect on their efficacy (Augutine-Shaw \& Funk, 2013). Other studies were conducted to trace the experiences of educational practicitioners in a principal preparation cohort program (Browne-Ferrigno, 2003). Researchers conducted an exploratory case study design with 18 participants and results 
revealed one-on-one collaboration with real-life administrators an integral component of leadership development.

In sum, mentoring has deep historical roots stemming from Greek mythology. In the modern era, mentoring emerged in the business realm to develop strong business leaders. Since that time, mentoring has infiltrated many other professions including healthcare and education. An additional purpose of reviewing this literature is to highlight the use of mentoring in education. In doing so, mentoring plays an integral role in the development of teachers and school leaders. In education, mentorships can be beneficial in retaining teachers and school leaders. Mentorships are beneficial in supporting new or novice personnel. While mentorship researchers outline the specific role groups (i.e. teachers, assistant principals, future school leaders) currently utilizing mentorships for development, the existent literature fails to show how educators in other roles, including academic instructional coaches, are mentored. While it appears mentorships for these role groups exist, the specificity in which mentors are supporting these groups would not benefit academic instructional coaches. In other words, it may be difficult for academic instructional coaches to develop mentorships because current systems are not in place to do so. If, in fact, academic instructional coaches are having access to these types of mentorships, the mentoring most likely is not addressing an academic instructional coach's needs. For example, Hudson's (2007) model for the mentoring of teachers includes five areas centering on mentoring geared towards improving instruction. Further, school leadership development programs focus on human resources, budgeting, and staff development (Normore, 2007). In other words, if a coach is seeking support, he or she may do so by participating in a program designed for teacher 
and leader development and retention. A coach may not benefit from the available teacher or administrative mentorships, because their roles and responsibilities differ. Thus, many academic instructional coaches are not receiving mentoring or support similar to that of their counterparts in more traditional roles. Even if this is not the case, and academic instructional coaches receiving mentoring, more research may show if and how this occurs.

\section{Academic Instructional Coaching}

Prior to exploring mentoring's uses to support academic instructional coaches, a look into the roles and definitions of coaching must be examined. The first mention of the idea of academic instructional coaching emerged during the 1980s by researchers Joyce and Showers (1981). Their work, rooted in teacher development, is the first to recognize the learn, implement, and feedback learning cycle (Joyce \& Showers, 1981; Denton \& Hasbrouck, 2009; Showers, 1985). Essentially, these researchers found teachers learned best when they participated in a professional development session, had the opportunity to implement the new knowledge they gained in a classroom context, and received feedback based on implementation (Showers, 1985). Further, someone who was either a peer or an outside resource could lead this process (Showers, 1985). Joyce and Showers (1982) liken the coaching process to that of an athletic coach.

As more knowledge of coaching continued to mount through the 1980s and 1990s, academic instructional coaching received formal legitimacy via accountability efforts in the 1990s and 2000s. This was the result of new funding and legislation supporting the coaching approach (Denton \& Hasbrouck, 2009). For example, the passing of the Reading Excellence ACT (REA) promoted the improvement of reading in 
elementary school by providing grant funds to low performing schools. A portion of this funding was directed for professional development. As such, many schools purchased reading coaches to support program implementation (Denton \& Hasbrouck, 2009). In another example, a portion of NCLB, known as Reading First, stipulated the use of coaching in program implementation. As a result, thousands of coaches were hired in elementary schools (Denton \& Hasbrouck, 2009). Lastly, Denton and Hasbrouck (2009) argue the large push for Response to Intervention (RTI) programs, which resulted from the reauthorization of the Individuals with Disabilities Education Act, has created opportunities for many schools to hire coaches to aid in RTI implementation.

\section{Roles and Benefits of Academic Instructional Coaching}

The placing of academic instructional coaches in schools, can ultimately work to improve student achievement. This is important given most coaches are hired to raise accountability scores (CCE, 2001, Guinney, 2001). Significant positive outcomes are also seen in academic instructional coaching (Eisenberg \& Medrich, 2013). Ross (1992) showed student academic achievement improved in a study on academic instructional coaching. Similarly, Onchwari and Keengwe (2010) found reading and writing scores improved when teachers collaborated with a coach.

Today, many academic instructional coaches serve in schools as a way to support state and federal accountability measures (Marsh et al., 2012; Rush \& Young, 2011; Shidler, 2009; Stock \& Duncan, 2010). However, the explicit role and definition of the modern academic instructional coach remains convoluted (Denton \& Hasbrouck, 2009). Much of the confusion is due to the various roles academic instructional coaches perform (Walpole \& Blamey, 2008). For example, academic instructional coaches perform 
many of the following tasks: implement state level curriculum, model teaching, manage student learning data, run team meetings, lead professional development, and perform any other activity deemed necessary by school principals (Denton \& Hasbrouck, 2009; Deussen, 2007; Marsh et al., 2012; Rush \& Young, 2011; Walpole \& Blamey, 2008). In an attempt to understand how academic instructional coaches spend their time, Deussen (2007) undertook a study to answer the following research questions: who becomes a reading coach, what background, skills, and qualifications do coaches bring to their jobs, and how do coaches actually perform their jobs? Deussen (2007) used qualitative surveys to identify coach demographics. These data were then used to identify specific coaches that could be interviewed to better answer the questions at hand. Overall, the study included 203 coaches in five states. Deussen (2007) suggests four ways coaches utilize their time. Data-driven coaches spend $45 \%$ of their time in the analysis and interpretation of data related tasks (Deussen, 2007). Data related tasks include the analysis of student and school learning data. Most of this analysis is student and school performance data from mandated assessments. Another type of coach, student-oriented coaches, spend a majority of their time interacting with students. Not surprisingly, student-oriented coaches spend only 14 percent of their time working with teachers, and the remaining time working with students (Deussen, 2007). This is the opposite of teacher-oriented coaches. Teacher-oriented coaches spend between 41 percent and 52 percent of their time working directly with teachers (Deussen, 2007). Lastly, managerial-coaches spend a substantial amount of time maintaining and creating instructional systems at the school level (Deussen, 2007). Typically, these coaches are involved in the operational aspects of the school. They work to sustain and create the 
systems that allow the school to function on a daily basis such as the running of team or department meetings. This study is important as it successfully classifies the various tasks academic instructional coaches perform. At the same time, these, and the studies that follow, raise questions about why coaches are performing extensively different tasks in these roles.

While Deussen's (2007) study could work as a foundation in understanding the academic instructional coaching position, additional academic instructional coaching studies suggest other academic instructional coaching roles exist. For example, Walpole and Blamey (2008) conducted research outlining the specific roles of a coach identified after a full year of literacy coach implementation. Their analysis, which included semistructured interviews of 31 principals and coaches, explained the role of coaching as either director or mentor. Under the role of director, coaches where seen as either managers or trainers. Principals and teachers perceived the manager as a coach who is involved in the buying and organizing of materials, the scheduling of instruction, or the grouping of students based on data. In the director's realm, coaches served as trainers. In this role, it was the duty of the coach to promote assessment and curriculum growth. In another description of coaching roles, described as the mentor, those coached perceived coaches as either a teacher or a modeler. As a teacher, the coach was in charge of creating, implementing formal presentations for staff, designing, and implementing teacher group studies. In the modeler role, the coach was responsible for the modeling of instruction both in and outside the classroom. In addition to these four roles, two more coaching roles existed. These roles shared characteristics of both the mentor and director 
roles. Such roles, titled assessor and formal observer, focused on the utilization of data and observations in assessing and providing feedback to teachers.

Lastly, there is also significant research to indicate coaches mainly work in the areas of reading and literacy (Blamey, Meyer, \& Walpole, 2008). This is in response to many of the aforementioned federal and state programs seeking to ensure greater accountability in education; specifically, in basic literacy and numeracy skills. Accordingly, Blamey et al. (2008) set out to describe the current state of literacy coaching given the recent adoption of an established set of IRA literacy coaching standards. Blamey et al. used qualitative methods to analyze the results of a 25 -item web-based questionnaire containing both open and forced choice questions. Their results indicated coaches perceive themselves as performing three main roles. According to the coaches in the study, one of their primary roles was acting as a "collaborator" (p. 317). In this role, the coaches primarily worked to examine curriculum materials, best practices, and support teachers and students in their implementation. As the "coach" (p. 319), the literacy coach participated in assisting teachers in specific content areas, working with teaching teams, and demonstrating instructional strategies. Lastly, the "evaluator" (p. 320) role involved the review of assessment research, the standardization of scoring students' writing assignments, and the support of teachers in choosing instructional strategies designed to support achievement. While these findings were a part of a larger study designed to understand how well the IRA standards were being implemented by literacy coaches, the study provides an accurate snapshot of the role coaching due to its inclusion of 147 middle and high school coaches from across the United States. 
Another group of researchers has attempted to define and hone in on the specific nature of this job in the modern context. Denton and Hasbruck's (2009) comprehensive overview of academic instructional coaching research presents a sole attempt to provide a holistic view on how coaches coach. In their literature review, they agree the largest number of coaches work with teachers in the areas of reading and literacy (Denton \& Hasbrouck, 2009). Denton and Hasbruck (2009) also state seven academic instructional coaching models exist. While the overarching theme of each of these models is to improve teaching, each model serves a different purpose and contains varying coaching strategies and styles. Ultimately, the different coaching strategies and styles make it difficult to solidify the roles of the coach. Of similar uselessness, the researchers discuss many of the roles mentioned above, but fail to present an all-encompassing view of the roles of instructional mentors.

In the existing literature, the articles attempt to outline the roles of the academic instructional coach as beneficial, but they also highlight many discrepancies in the roles coaches perform. To add to the ambiguity of the role, the job titles given to academic instructional coaches are also inconsistent. Academic instructional coaches have other labels, such as instructional facilitators, literacy coaching, coaches, reading specialists, and even consultants (Denton \& Hasbrouck, 2009; Rush \& Young, 2011; Stock \& Duncan, 2010; Walpole \& Blamey, 2008). Further, researchers disagree about the actual roles academic instructional coaches perform. For this reason, most studies are unable to outline the vast roles of the academic instructional coach clearly and many questions exist on the role academic instructional coaches perform. In relation to the current study, it could be possible these coaches are working in areas in which they are the most 
comfortable, feel most efficacious, or have the most support. In other words, if a new coach is provided mentoring from a more experienced coach in a specific area, (i.e. student-oriented coaching) might the new coach be more apt to act as a student-oriented coach? One could also assume coaches are performing many different tasks because they lack specific training or support. So, if mentoring and coach support is not available, coaches may be haphazardly choosing the ways they work within a school. Now, there is not substantial research to determine if this is the case. More research is needed to better understand the role mentoring plays in the ways coaches coach and develop.

It is also important to understand who becomes an academic instructional coach. This is necessary in understanding the ways in which coaches may be qualified and prepared for the jobs they fulfill, given the numerous roles outlined previously. A review of the educational experiences and backgrounds of coaches will help determine if coaches are prepared to fulfill these roles. Several articles shed light on this topic. Deussen (2007) provides a general overview of academic instructional coaches' demographics in Alaska, Arizona, Montana, Washington, and Wyoming. In this case, most academic instructional coaches are comprised of former teachers with approximately 17 years previous teaching experience. Most coaches emerge within their current school from a teaching position. Fifty-one percent of coaches have a master's degree in an education related field. In the Deussen (2007) study, nearly all coaches had master's degrees in literacy. To support Deussen (2007), Blamey et al. (2008) national survey on academic instructional coaches at the secondary level indicates similar findings. In doing so, a majority of middle and high school coaches have teaching degrees and certificates in 
teacher education. Further, more than half of the participants had graduate degrees in education, literacy, or an area outside of education.

Most importantly, these studies suggest that academic instructional coaches typically do not have experience in the area of coaching. As former teachers, these coaches have experience in creating assessments, planning lessons, and guiding student learning. These skills required for teaching are much different the skills required for the roles of academic instructional coaches outlined above. This idea, coupled with the fact that many coaches have degrees in teaching and learning, rather than degrees promoting the skills of a coach, may indicate coaches are not prepared to fulfill their duties because of a lack of training. In academic instructional coaching development, research indicates coaches feel unprepared and seek more supports.

\section{Training Academic Instructional Coaches}

Research on academic instructional coach support and development is unclear, and suggests academic instructional coaches are ultimately, not supported. While some academic instructional coaching programs do exist to support academic instructional coaches in their roles, not all are effective. Academic instructional coaches often report the need for more support. Research on academic instructional coaches overwhelmingly reveals coaches receive poor training and lack experience in the role of coaching (Deussen, 2007; Stock \& Duncan, 2010). Deussen (2007) revealed nearly all reading coaches had no previous experience in coaching. The coaches with experience typically had between one and three years of experience as a coach (Deussen, 2007). Other studies revealed academic instructional coaches need for training and experience in coaching. Of the 171 coaches interviewed by Blamey et al. (2008), only 37 percent reported of 
working with a mentor. According to Blamey et al., most of the training provided to academic instructional coaches is through district-level professional development, graduate level coursework, or professional readings. Of the three, coaches rated graduate-level coursework the most helpful. Coaching trainings conducted via study groups and state-level professional development were merely seen as helpful by only 13 percent and 19 percent participants (Blamey et al., 2008).

While some coaches may be able to coach effectively without experience, other studies stress a need. In a study analyzing the effectiveness of professional development for coaches who will be supporting struggling teachers, Ambrosetti (2014) found many coaches expressed the importance of professional development in improving their own practice. The researchers in this study set out to discover the perceived impact of a twoday professional development program for teacher mentors. Based on open-ended questionnaires, the participants indicated the training was useful and necessary as it changed the way the perceived the mentoring of teachers. While this study does not deal with coaches directly, the role of the mentor in supporting teachers as explained in the article is similar to the coach's role outlined previously (Walpole \& Blamey, 2008). Stock and Duncan (2010) support the notion of professional development for academic instructional coaches. Stock and Duncan (2010) examined instructional facilitators, Wyoming's version of an academic instructional coach, perceived a need for support. They surveyed 171 academic instructional coaches and found 90 percent of new academic instructional coaches expressed a need for mentoring. Specifically, these coaches requested support in the areas of instructional leadership, data usage, and working with difficult staff. This is further supported by Gibson (2005), who claims 
teachers need more than their own experiences in the classroom to support other teachers. In this case study of two academic instructional coaches at a primary school, coaches self-reported that many teachers were not in a position to coach and were reluctant to change. Because of this, coaches need more training in understanding teachers' opinions and actions. More appropriately stated, "Simply being experienced as a teacher and having success in the classroom does not always translate to effective academic instructional coaching" (Gibson, 2005, p. 65).

Similarly, Marsh, McCombs, and Martorell (2012) conducted as a study of Florida academic instructional coaches to attempt to understand the specific policies and practices districts utilized to support coaches. This analysis also included an evaluation of current coaching practices as perceived by coaches. Their analysis revealed most coaches valued professional development, but called for more support in working with adult learners. In this comprehensive study of middle school coaches, Marsh, McCombs, and Martorell first used quantitative surveys to identify coaching demographics across the state. From these data, they selected individual districts for qualitative analysis. Interviewed participants included district personnel, teachers, and coaches.

It is also important for coaches to receive training in the specific areas in which they will be supporting teachers (Rush \& Young, 2011). For example, if a teacher needs support in the area of technology, the coach must also have experience and training in this realm. These types of issues complicate the ways in which coaches can be supportive. In other words, coaches must have a wide range of skills to be able to support a wide range of teacher needs. Coupled with the low experience levels 
mentioned previously, this can make it extremely difficult for academic instructional coaches supporting numerous teachers within a building effectively.

Overall, this research helps to solidify the point that switching from teaching to coaching is different (Denton \& Hasbrouck, 2009). Academic instructional coaches lacking the experience and training lack key supports. While an academic instructional coach may have strong capabilities as a teacher, this does not always translate into effective coaching, as the two require completely different skill sets (Deussen, 2007). Further, academic instructional coaches recognize and request a need for more support. Much of this support must be different from the trainings academic instructional coaches received as teachers. Ultimately, the above research indicates a strong need for the understanding of academic instructional coaching support. The research literature reveals little or no supports provided to academic instructional coaches, but existing studies fail to determine, from a coach's view, how development is currently occurring. In other words, the field will benefit from additional research on how to understand the mentoring of coaches.

\section{Theoretical Underpinnings of Coaching Mentors}

The social constructivist epistemology guides the design of this study. According to Crotty (1998), constructivism is the process of making meaning of the world in which one lives. Social Constructivism emphasizes the importance of human interactions in making this meaning (Creswell, 2012). Further, an individual's reality forms from the feelings, assumptions, and perceptions that develop out of one's experiences and interactions (Crotty, 1998). In alignment with this belief, socio-cultural learning theory will represent the theoretical framework for this study. This theory, initially introduced 
by Vygotsky (1978), outlines that learning is an essentially social process, situated within cultural, institutional, and historical contexts. Further, this learning is facilitated by a more knowledgeable person who typically assists, models, observes, and provides feedback to support individual development (Vygotsky, 1978). Used in similar existing academic instructional coaching studies (e.g., Galluci, Lare, Yoon, and Boatright, 2010; Huguet, Marsh, \& Farrell, 2014; Marsh, \& Farrell, 2015). Huguet, Marsh, and Farrell (2014), define socio-cultural theory as "learning [that] happens as a social process, occurring among peers and within an environmental context" (p. 6). In each of these studies, socio-cultural learning theory was used to better understand how staff our developed socially, within a context. Researchers used this theory to better understand the specific ways administrators mentored and developed teachers within their building. Further, the researchers expanded on Vygotsky's work by providing specific language for how the social constructivism theory specifically plays out in interactions between a school leader and staff. Specifically, Marsh and Farrell (2015) outline tasks such as observations, modeling, feedback, and dialogue to explicitly identify the social relationship between the learner and teacher. Given the nature of this study, this lens is most appropriate for understanding the relationships between academic instructional coaches and principals.

Therefore, the goal of this research study is to understand the specific ways participants comprehend the role of academic instructional coach mentoring as they experience it on a daily basis, and within their interactions with more experienced peers. In other words, this theoretical approach allows the researcher to understand the specific ways academic instructional coaches understand mentoring as it relates to their own 
position and in supporting teachers in their school. See Figure 1 for an overview of the theoretical framework provided for this study.

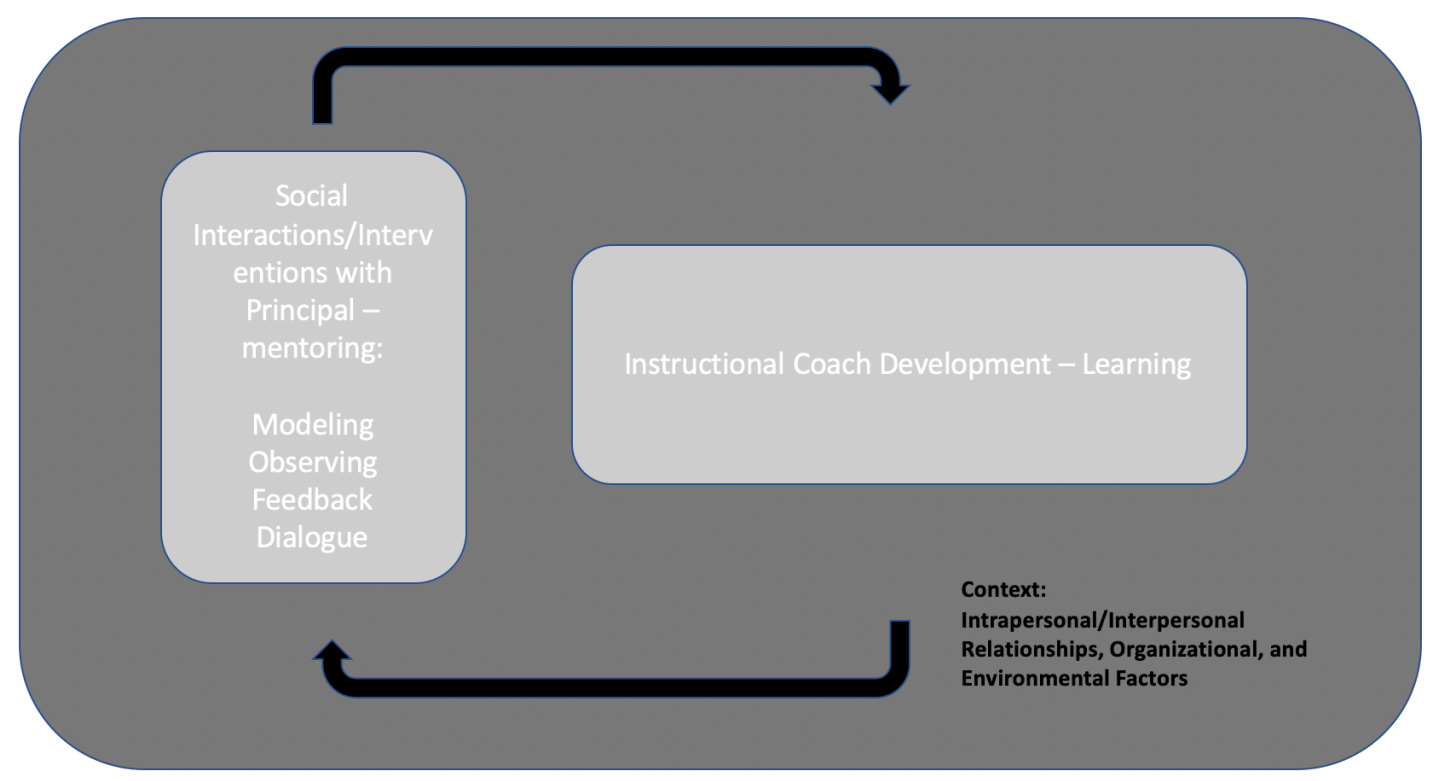

Figure 1. Conceptual Framework

From the synthesis of the literature, academic instructional coaches receive little or no mentoring in preparation for their various roles as an academic instructional coach. For example, mentorship research has historically focused solely on pre-service teachers, new teachers, and teachers preparing for administrative positions (Copeland \& Calhoun, 2014; Normore, 2007; Washington, 2007). Therefore, current research does not address the mentorship of other teaching groups and related school positions. This includes teachers who are not new and do not wish to become school principals. Specifically, for the purpose of the current research, this includes academic instructional coaches.

Research supports this in two ways. First, limited research on the role of mentoring in academic instructional coaching as a whole is limited (Walpole \& Blamey, 2008). This is supported by Stock and Duncan (2010) who explain, "While some research exists around 
the topic of mentoring teachers and administrators, there is a scarcity of studies that explore the use of mentoring of academic instructional coaches" (p. 58). Existent research not only highlights this gap, but also expresses a large need for preparation and development programs to combat the significantly low experience levels exhibited in academic instructional coaches (Deussen, 2007; Rush \& Young, 2011). Included in this future research, should be the creation of a definition to "...define what it means to be competent working with adult learners and the pedagogical knowledge and skills needed to ensure this competence" (Marsh et al., 2012, p. 23).

Therefore, given the limited research on how to improve the professional development of academic instructional coaches and how this development is occurring, additional research is needed. As such, the purpose of this qualitative study is to understand the role of mentorship on academic instructional coaches in an AIS school in the era of accountability. The following research question(s) will provide guidance for the study: 1) How are academic instructional coaches developed and mentored in an AIS school context? and 2) What development strategies do academic instructional coaches perceive as beneficial to their development? In alignment with previous research on this topic, an exploratory case study design utilizing both semi-structured interviews and field notes for data collection seeks to answer these questions.

The findings of this research study could have significant implications for policy and practice. First, for the district that serves as the context for this study, findings can inform the design of a formal instructional mentoring program currently not in existence within the district. Further, this research study could help future principals understand how to support these typically inexperienced coaches as they work to fulfill school level 
goals. Second, this research study could identify a more effective and efficient method of academic instructional coaching implementation. In other words, better understanding of how to support these academic instructional coaches in the fulfillment of their duties may clarify the specific ways schools and districts utilize academic instructional coaches, and, in turn, allow for more effective coaching. Ultimately, an academic instructional coach improved through the mentoring process could more effectively provide support to teachers. This support could create improved teacher efficacy, teacher retention, and lead to higher achievement gains desired by many in this era of accountability. 


\section{CHAPTER III: METHODOLOGY}

In this study, a collective case study was employed to better understand how academic instructional coaches are mentored. According to Miles, Huberman, and Saldana (2014), "the main task is to describe the ways people in particular settings come to understand, account for, take action, and otherwise manage their day-to-day situations" (p. 9). In the same way, the proposed research attempts to understand how academic instructional coaches understand and perceive their development through mentoring while working in an AIS school context. Qualitative methods will also be used in opposition to extant previous research utilizing quantitative approaches. While this research has been influential in identifying the demographic characteristics and need for academic instructional coaching development, such research has failed to identify the ways academic instructional coaches are currently being developed (Deussen, 2007; Stock \& Duncan, 2010).

Alongside a rationale for the chosen methodology, this chapter details the sources and means by which qualitative data were collected. Furthermore, this chapter discusses the process by which the collected data were analyzed. The research collection and analysis protocols will be supported with appropriate context and an understanding of the research participants. This chapter also will discuss the steps taken to ensure credibility, transferability, dependability, and confirmability. Lastly, this chapter will conclude with 
an identification of potential researcher ethical issues and a discussion of researcher positionality.

\section{The Purpose and Research Questions}

Drawing upon prior research indicating academic instructional coaches are typically underprepared to carry out their duties effectively, the purpose of this study is to understand the mentoring of academic instructional coaches in an AIS school context. Further, in an effort to better prepare and improve the efficacy of these positions, this study aims to identify specific strategies school leaders and academic instructional coaches can perform to increase coaching effectiveness. This study will fill current gaps around academic instructional coaching in a modern AIS school context. In many examples, current research studies solely focused on the implementation of coaching across settings and contexts. Most of this research has also worked to understand the implementation of academic instructional coaching in general. Little research exists attempting to understand the development of the academic instructional coach in an AIS school context. Knowledge in this area is extremely important, as many educational leaders adopt academic instructional coaching as a school improvement strategy (Marsh et al., 2012; Rush \& Young, 2011). The following research questions will provide the guide for this study: how are academic instructional coaches developed in an AIS school context? What development strategies do academic instructional coaches perceive as beneficial to their development?

\section{Context of the Study}

This study takes place in a large urban school district in the southeastern United States. This district is the largest in the state and serves approximately 101,000 students 
in 156 schools. Historically, this district has been pressured to make massive changes as it contains some of the lowest performing schools in the state. One of the many initiatives currently implemented in this district has been the provisioning of all elementary, middle, and high schools with an academic instructional coach.

Initially, these academic instructional coaches were current district teachers hired and placed by the district via informal requests by school principals. At the onset, this created issues with accountability and oversight as the district struggled to oversee these positions and principals battled for more control over the role. Coupled with the initial absence of a formal job description, this gave academic instructional coaches little clarity as to whom they are accountable to and whom they would look to for mentoring. Dueling agendas amongst district and school level administrators also complicated the academic instructional coach's role in this district. While the district still provides professional development and support, academic instructional coaches now report directly to the principal. A current job description highlights ten job duties relating to the development of teachers and school initiatives, including an overarching duty in carrying out any task the principal deems necessary. The job's previous official title, Goal Clarity Coach (GCC), has further convoluted how stakeholders understand the role. At present, the district places additional academic instructional coaches in schools as content specialists, and are provided as additional staffing to schools who may already have a traditional academic instructional coach. Many of these current positions were an attempt by the district to get more hands on support into the schools. Most recently titled, academic instructional coaches, this creates further confusion, as the coaches must more frequently deal with balancing school and district level directives. In relevance to 
this study, it may also influence the types of supports and mentoring coaches receive, given their added interactions with district administration.

\section{Participants and Sampling}

This district and participants were selected purposively for a variety of reasons. Purposive sampling allows the researcher to identify individuals and sites best suited for addressing the research question(s) (Creswell, 2012). The participants were chosen from this district for having a relatively large number of academic instructional coaches working in AIS schools. This provides a large number of potential participants who have consistent experience levels in similar contexts. The infancy of this position in the district is also critical. The title and role of the Academic instructional coach (AIC) position has only existed for three years, and likely participants may lack in-depth experience and have likely sought or been provided some level of mentoring. This is important, as it will be possible to understand how these AICs perceive their development and support as they are currently receiving it, or as they will have recently received support. Ultimately, this provides for data richness, as participants will likely have retained much of their memories regarding the development process given the limited time span in which this development may have occurred. Another reason their selection is because the coaches in the participating district are a reflection of coaches seen in previous studies (Deussen, 2007; Rush \& Young, 2011). For example, many of the descriptors of the academic instructional coaches in previous studies; former classroom teachers, limited previous experience, and little formal training are similar to those in this district. This is evidenced in the hiring qualifications outlined by the district. These qualifications specifically describe a candidate's successful teaching of at least five years. 
Given the nature of the mentor and mentee relationship, it will also be necessary to conduct research on AIS school principals who have hired and placed academic instructional coaches in their schools. This is essential to understanding the specific ways academic instructional coaches may seek support from their administrators. According to Kram (1985), the mentee will rely heavily on the information and support provided by the mentor, who is typically in an experienced or overseeing role. In the case of schools, it is only natural for the mentee to seek development and support from the school principal who works in a similar experienced and overseeing role within the school.

Criterion sampling was used to identify specific participants within the context above. Criterion sampling was employed as it allowed the researcher some level of quality assurance (Creswell, 2012). The criterion sampling served to "bind" the case (Yin, 2014). In identifying a potential sample, employment in an AIS school setting was be essential. As defined by the state in which these schools operate, an AIS school has consistently failed to meet the targeted accountability benchmark. Participants were also employed in the district outlined above. This is necessary as the consistency in which the implementation of academic instructional coaching in this district means most participants have a demographic and experience level similar to that seen in previous research. Middle and High Schools will also inform the context from which participants are selected. The research supports this choice. As previously mentioned in the Blamey et al. (2008) research, and highlighted by the Walpole and Blamey (2008) study, most academic instructional coaches are hired to work in elementary schools and have backgrounds solely at the elementary level. Outside Blamey et al. (2008), few studies 
exist describing the definition, roles, or experiences of academic instructional coaches at the secondary level. In fact, the researchers indicate a need for more research on academic instructional coaches at the secondary level. At the beginning of this research, 18 AIS middle and high schools existed in the district that served as the context for this study.

Utilizing the above criteria and approach, AIS schools were identified using the state's online list of AIS schools. Middle and High schools housed within the identified district were reviewed and participants were then selected using a master list of AIC's and principals provided by the district. This list provided the researcher with 48 potential participants. The researcher aimed to identify at least 10-12 respondents for data collection. Once identified, these individuals were contacted via an email detailing the study and asking for participation. In response to the emails, the researcher received 16 response emails indicating a willingness to participate in the study (Tables 1 and 2). This number, identified by Creswell (2013), is suitable for the approach, and within the range outlined by Yin (2014). The study participants were provided and signed the informed consent outlined in Appendix A. 
Table 1. Principal Participants and School Demographics

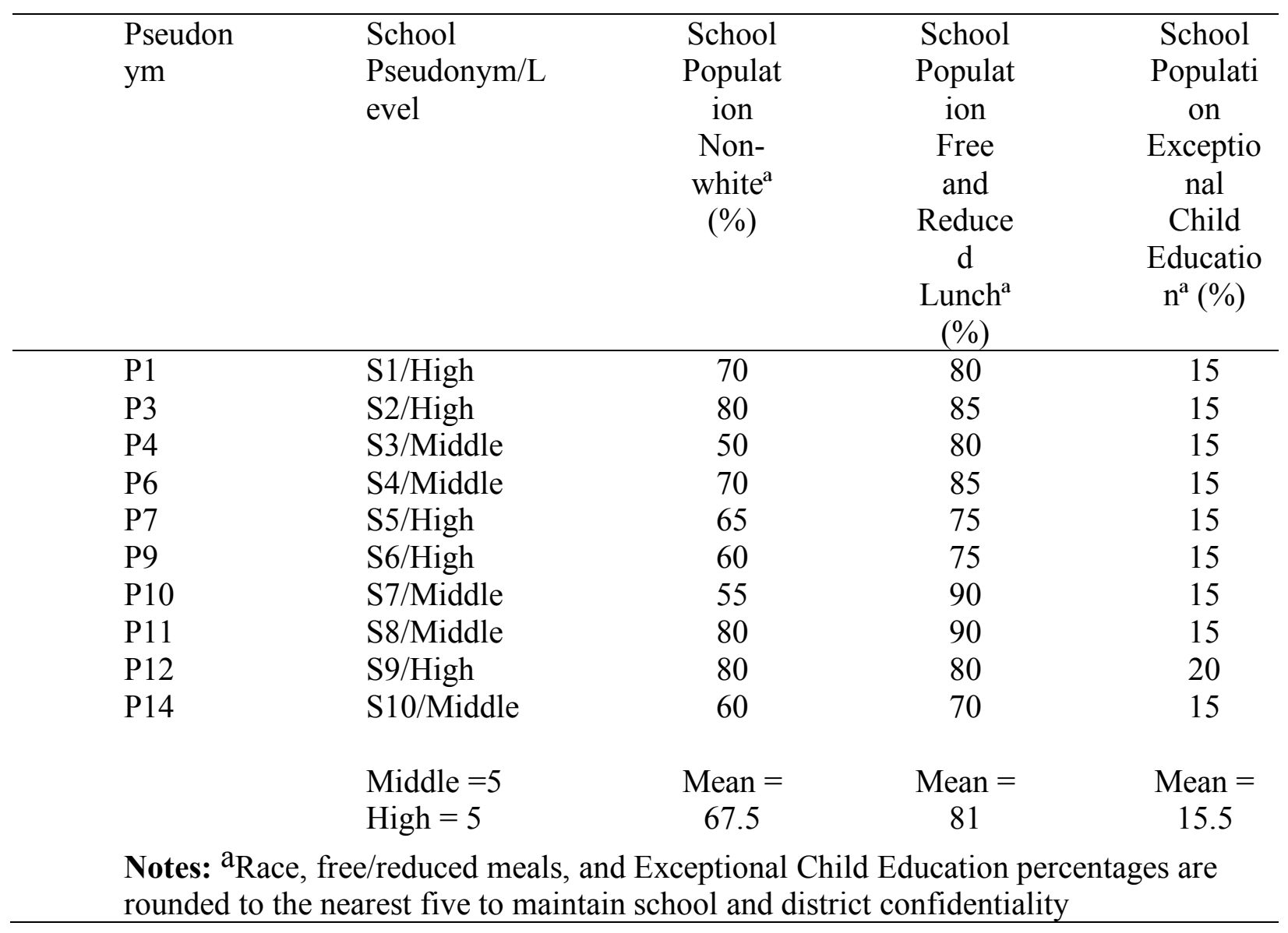


Table 2. AIC Participants and school demographics

\begin{tabular}{|c|c|c|c|c|}
\hline $\begin{array}{l}\text { Pseudon } \\
\text { ym }\end{array}$ & $\begin{array}{l}\text { School } \\
\text { Pseudonym/L } \\
\text { evel }\end{array}$ & $\begin{array}{c}\text { School } \\
\text { Populat } \\
\text { ion } \\
\text { Non- } \\
\text { white } \\
(\%)\end{array}$ & $\begin{array}{c}\text { School } \\
\text { Populat } \\
\text { ion } \\
\text { Free } \\
\text { and } \\
\text { Reduce } \\
\text { d } \\
\text { Lunch }^{\mathrm{a}} \\
(\%)\end{array}$ & $\begin{array}{c}\text { School } \\
\text { Populati } \\
\text { on } \\
\text { Exceptio } \\
\text { nal } \\
\text { Child } \\
\text { Educatio } \\
\mathrm{n}^{\mathrm{a}}(\%)\end{array}$ \\
\hline G7 & S5/High & 65 & 75 & 15 \\
\hline G8 & S11/High & 70 & 90 & 20 \\
\hline G11 & S8/Middle & 80 & 90 & 15 \\
\hline G12 & S9/High & 80 & 80 & 20 \\
\hline G14 & S10/Middle & 60 & 70 & 15 \\
\hline \multirow[t]{2}{*}{ G15 } & S10/Middle & 60 & 70 & 15 \\
\hline & $\begin{array}{l}\text { Middle = } 3 \\
\text { High = } 3\end{array}$ & $\begin{array}{c}\text { Mean }= \\
69.1\end{array}$ & $\begin{array}{c}\text { Mean }= \\
79.1\end{array}$ & $\begin{array}{c}\text { Mean }= \\
16.6\end{array}$ \\
\hline $\begin{array}{l}\left.\text { Notes: }{ }^{a}\right] \\
\text { rounded }\end{array}$ & $\begin{array}{l}\text { reduced mea } \\
\text { est five to }\end{array}$ & $\begin{array}{l}\text { ceptional } \\
\text { lool and }\end{array}$ & $\begin{array}{l}\text { ducation } \\
\text { onfidenti }\end{array}$ & es are \\
\hline
\end{tabular}

\section{Strategy of Inquiry}

Falling under the realm of qualitative research, a collective case study design was used to better understand the research questions. In addition to suitability with education research as a whole, case study methodology is appropriate for understanding a modern contextual problem in an in-depth manner (Yin, 2014). Given the specific context in which this research occurred, a case study allowed the researcher an opportunity to understand the intricate relationships, experiences, and perceptions unable to be captured in other forms of research. This inside look of academic instructional coaches' and principal's perceptions will provide more specific information about how coaches are mentored and developed. This case study methodology is also appropriate as it has been used by other researchers in the field to understand academic instructional coaching 
development (Galluci, Lare, Yoon, and Boatright, 2010; Huguet, Marsh, and Farrell, 2014). Further, case study research seeks to address the "how" in research questioning (Yin, 2014). This is in alignment with the research questions guiding this study. For example, a case study method also addressed many of the gaps current research suggest exist as a result of not completely understanding how academic instructional coaches are developed in their individual contexts. Specifically, a collective case study methodology was be employed. A collective case study involves the selection of numerous sites to illustrate a broad view (Creswell, 2012). Multiple sites were selected to highlight different perspectives on the issue (Creswell, 2012). This method was necessary because there is only one AIC and one principal at each school. More sites were needed to ensure data richness. Lastly, this multiple-case study design also increases the likelihood of repetition and provide more robust research overall (Yin, 2014)

\section{Data Collection Procedures}

Once the Institutional Review Board approved and participants were identified, the data collection process began. A variety of data collection techniques were employed. According to Yin (2014) and Creswell (2014) interviews, field notes, and documentation are appropriate for case study data collection. Each of these methods were used to gather data from participants. First, semi-structured interviews were conducted with each participant utilizing the techniques outlined by Yin (2014). An interview protocol was used in similarly in each of the interviews. In this study, interview protocols were developed to probe participants' understanding of the role mentorships have in shaping their development. The four protocol stages outlined by Yin (2014) were used; overview of the case study, data collection procedures, data collection 
questions, and how the case study findings will be reported. For added reliability and clarity, the interview protocol was reviewed by peers and non-participating academic instructional coaches (Miles, Huberman, and Saldana, 2014). The interview protocol was created by the researcher and was used similarly in all interviews. The interview protocol for both the academic instructional coach and the principal can be found in Appendix B and $\mathrm{C}$ respectively. Each participant participated in one interview. Interviews for academic instructional coaches lasted approximately one hour. Out of respect for time, principal interviews lasted approximately 45 minutes. These shorter case study interviews were appropriate for gathering ample qualitative data (Yin, 2014). Interviews took place towards the end of the school year and summer to provide new hires adequate time to adjust and learn about the academic instructional coaching position. The interviews were completed solely by the researcher and recorded using a voice recorder for accuracy and clarity. In an effort to provide a comfortable environment for the participant, interviews occurred at a location and time specified by the participant. Second, field notes and observations were used as an additional source of data (Creswell, 2012). These field notes were taken throughout the entire data collection process. These field notes were contained in a researcher's notebook that accompanied the researcher during each interview. Within these notes, the researcher documented additional observations, participant reactions, or events occurring before, during, or after the interview (Creswell, 2012). Third, the researcher relied on the use of documentation to better understand how academic instructional coaches are mentored. Artifact collection is beneficial for case study research because of its permanency, specificity, ability to be unobtrusive (Yin, 2014). For the current research, specific documents were shared by the 
participant at the request of the researcher. Throughout the research, participants provided little artifacts that were relevant to the research questions. This included the gathering of emails, academic instructional coaching training materials, and overarching school instructional and management plans. meeting minutes (Yin, 2014).

\section{Data Analysis}

Once all data were collected, the researcher transcribed the field notes, documents, and interviews and placed transcriptions in the Dedoose coding software. According to Creswell (2012) and Miles, Huberman, and Saldana (2014) a computer program provides an efficient way to manage and collect data. It also allows the researcher easy access to memos and documents (Creswell, 2012). In alignment with a collective case study, data was analyzed using a cross case theme analysis (Miles, Huberman, \& Saldana, 2014). Cross case theme analysis works to identify themes across all cases (Creswell, 2012). The first step in the data analysis process was to holistically read through all interview transcriptions, documents, and field notes using an inductive process (Creswell, 2012). Upon re-reading the transcriptions, the researcher began the first cycle coding process outlined by Saldana (2014). During this initial coding, the researcher used In Vivo coding. In Vivo coding allows the researcher to use the participants own words in phrases in the coding process (Miles, Huberman, \& Saldana, 2014). The coding process was chosen due to its ability to capture the academic instructional coaches own voice (Saldana, 2014). Additionally, it was important to utilize the conceptual framework in the coding process. Deductive coding was also used during this stage of the data analysis process. Specifically, the researcher relied on key words identified by previous research utilizing the social constructivist lens. Those specific 
codes, modeling, feedback, relationship building, and dialogue, identified by Vygotsky (1978) and Marsh and Farrell (2015) were also selected as a part of the coding process. Once this initial coding process was complete, codes were reviewed for patterns and themes (Saldana, 2014). Specifically, the researcher used pattern coding during this second cycle coding process (Saldana, 2014). While pattern coding is in alignment with the In Vivo coding, it was specifically chosen for its connection to the theoretical framework of the student. Specifically, this process was chosen because it allows for the examining of social networks and patterns of human relationships (Saldana, 2014). Once the first and second cycle coding processes were completed, the researcher began the cross-case theme analysis process. In doing so, the researcher used a variable oriented approach. As described by Miles, Huberman, and Saldana (2014), the variable oriented approach allows the researcher to look at specific patterns and themes that may arise out of all of the cases, rather than a comparison of each case. This iterative process continued until overall themes are identified. These emergent themes were then used to better understand the ways in which academic instructional coaches understand their own personal mentoring experiences.

\section{Strategies for Ensuring Credibility, Transferability, Dependability, and Confirmability}

Several strategies were used to ensure the credibility, transferability, dependability, and confirmability of the findings. Throughout the data analysis process, the researcher sought to triangulate various sources of (Creswell 2013; Yin, 2014). For example, the use of documents, interviews, and field notes allowed the researcher an opportunity to gather data from numerous sources and determine whether these various 
data sources confirm, clarify, or conflict with the others. Further, the use of cross-case analysis works to enhance and deepen the overall understanding of the academic instructional coach development issue (Miles, Huberman, \& Saldana, 2014). In an effort to increase dependability, the researcher utilized a member checking process outlined by Creswell (2012). Dependability issues were also mitigated by means of the standardized interview protocol used throughout the data collection process (Yin, 2014).

\section{Researcher Positionality}

Lastly, it is important to note the positionality of the researcher. As a former academic instructional coach in the district being studied, the researcher has potential to bring personal biases to the data collection and analysis process (Yin, 2014). Further, the researcher has continued to work in this district as an assistant principal, principal, and district administrator. While each of these roles is unique, they have all been within the same district. This may provide biases limited to the researcher's particular context. Additionally, the researcher, having worked in numerous schools within the district, has professional relationships with many of the participants outside of the research which may impact analysis. For these reasons, the researcher will also utilize a peer debriefing process in an effort to enhance the accuracy of the account (Creswell, 2012). Ideally, this person, using questioning, can attempt to identify and eliminate any personal biases that may be present as a result of my own personal experiences in academic instructional coaching in this context. 


\section{CHAPTER IV: RESULTS}

In this Chapter, the results of the study will be outlined. The following research questions guided the development, design, and delivery of this study:

1) How are academic instructional coaches developed and mentored in an AIS school context?

2) What mentoring supports do academic instructional coaches perceive as beneficial to their development?

To answer these questions, this section will be outlined in three different sections. The first two sections will review the data analysis and results for each of the two research questions, respectively. The third section serves as a summary of the findings and brings to light how each of the answers to the research question address the underlying context with which coaches and principals conduct work. It is important to note that in presenting these finding, pseudonyms were used to identify participants and provide anonymity to the participants.

\section{The Development of Academic Instructional Coaches in AIS School Contexts}

In answering the first research question, it is important to note that data analysis yielded different perspectives on the role of mentoring in the development of academic instructional coaches based on the participants' role. What follows are 1.) Perceptions of the development and mentoring of academic instructional coaches from the perspective of the principals interviewed for this study; 2.) Perceptions of the development and mentoring of academic instructional coaches from the perspective of the academic 
instructional coaches interviewed for this study; and 3.) A cross-case analysis, summarizing the codes and themes that emerged from across all the schools that served as the context of this case study.

\section{Mentorship According to Principals}

Principals indicated the most clear and effective practice for mentoring and supporting academic instructional coaches was through informal processes. Principals used a variety of informal processes to communicate expectations, attack specific tasks, or provide coaches feedback (See Table 3). For principals, this informal feedback process is reactionary or on a need-to-act basis. In other words, a school related event would typically trigger an opportunity for the coach and 
Table 3. Principal's mentoring practices themes and codes

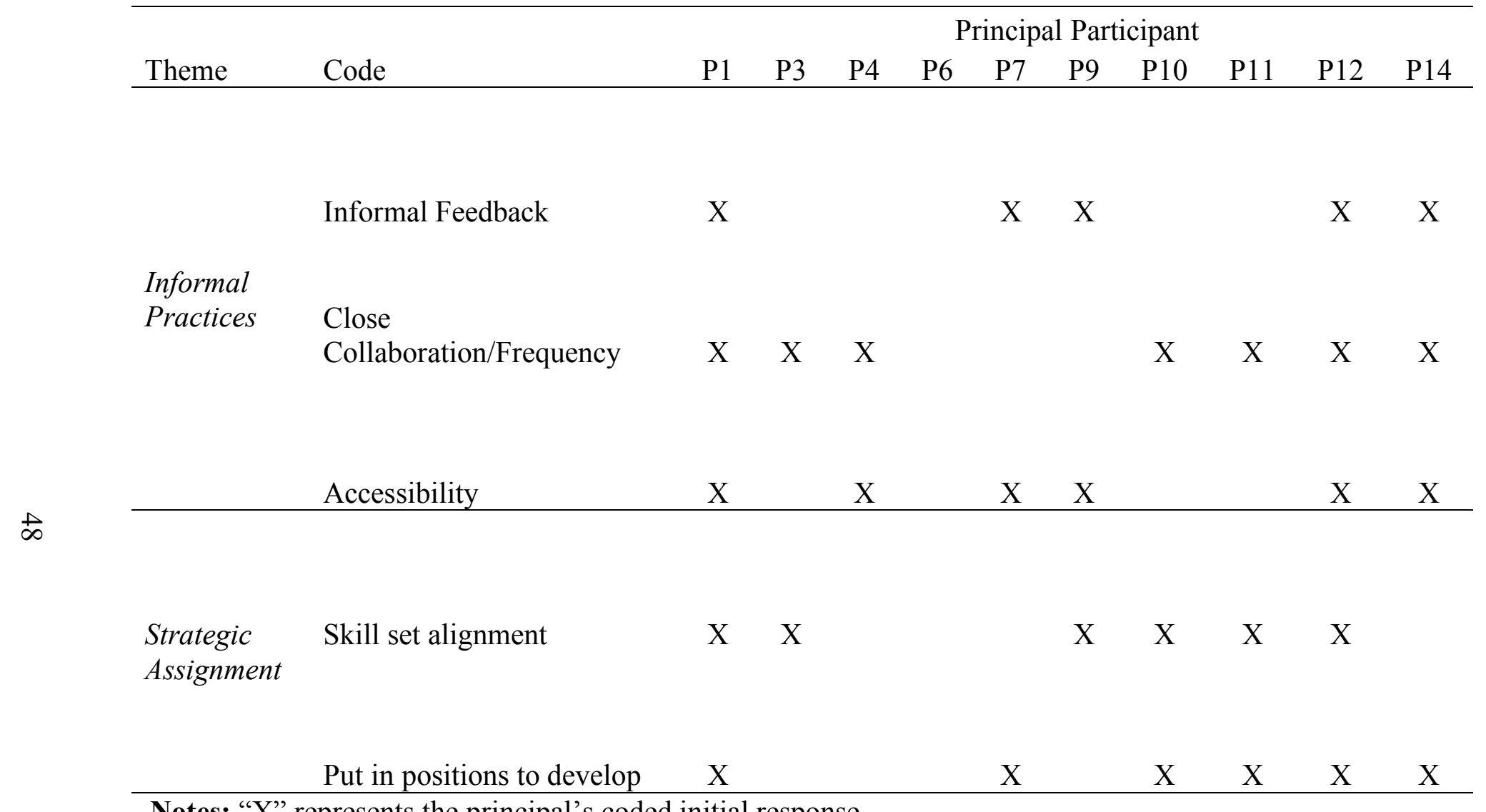

Notes: " $\mathrm{X}$ " represents the principal's coded initial response 
the principal to come together and interact. This interaction then leads to a situation where the principal would spend time with the coach providing specific direction to a task, outlining expectations, or collaborating to complete a task, or responding to a crisis. This is highlighted by Principal P7 explains:

So, she [the academic instructional coach] would have some of those moments and she wouldn't know how to handle it so she would come in to me and say that when you have a minute, can we talk. She would listen and I would coach her and then she would go do it. Pretty much every time that I can remember, [this] was successful. Principal P1 further highlights how many of these interactions manifest: Yea, we meet daily, formally and informally. You know, he is probably one of the number one people other than some of the academy principals that I call to talk or text. Not really run things by him, but to get information from him. To give him things to do. I'd say we interact daily anywhere from a half dozen times, and he'll basically be like these are the things that I'm working on, these are the things I need your feedback on.

What seems to be most important about the informal feedback structure, or lack thereof, is there are clear opportunities for the principals and coaches to collaborate and access one another. Accessibility to both the coach and principal is seemingly instrumental. This would seem natural given the lack of formal structures created or utilized by principals to interact with the coach. Three principals indicate formal meeting structures they use to develop academic instructional coaches; however, principals see the informal interactions as more instrumental in coach development. Principals also seem to establish a specific informal feedback mode to interact with the coach. Explained differently, principals seem strategic in the informal ways in which they provide 
guidance, directives, and feedback to coaches. An example of this would be through sending text messages, making a phone call, strategically locating an office in proximity to the principal, or unscheduled one on one conversations. Principal P4 highlights this in the following excerpt:

Oh gosh, well, we text each other all of the time. She's not on Twitter but I'm a voracious reader and I always have been. I use Saturday and Sunday mornings, if I'm not hiking, I make a pot of coffee and I just sit and I start reading. After I've shot her the fourth article, she's says stop! Go do something. Are you about done with that pot of coffee? Principal P1 emphasizes the importance of strategically placing the academic instructional coach's office near the principal, further promoting accessibility to the academic instructional coach. He explains, “...his office is right down the hall so he comes to me pretty often for support and guidance but he's gotten to the point where he can work pretty independently."

As P4 noted above, accessibility of the informal feedback may also be increased due to the ability of principals and academic instructional coaches being able to communicate by non-formal means outside traditional office hours. Several other principals also indicated the need and benefit of being able to access academic instructional coaches through a variety of means and times.

Frequency also plays a major role in the informal feedback coaches receive. Principals indicated informal interactions occurred daily, and in two instances, informal interaction took place more than two or three times a day. Therefore, according to principals, academic instructional coaches are getting timely feedback and support on their development. It does appear that the frequency of interaction lies solely on 
happenstance. If school events or district level tasks are not occurring, principals are less likely to interact with the coaches. An example would be from Principal P9, who explains:

Some days I may not talk to her. Her office is down the way and some days, you know for a few days in a row, we might be together the whole day depending on what we're doing. If we're meeting with PLCs that can be 3 or 4 days in a row with a day of planning and a day of a debriefing around it. If it's the end of the year after AP testing and testing was done with the end of your close out activities, I wasn't seeing her or spending any concentrated time working on stuff there you know for a couple weeks so it just kind of goes with the season.

Although principals indicated an overall lack of formal support systems for developing academic instructional coaches, they did emphasize and explain the importance of supporting coach development. Another theme highlighted by principals was to target the individual skill sets and aspirations of each academic instructional coach. Principals strategically worked to build capacity in their staff by putting them in positions and giving them opportunities to develop. Principals had a genuine desire to support the development of each coach. This theme manifested in several specific actions from principals. According to most principals, each of these actions focused on the overall development of the coach.

First, principals focused on matching individual coach's skill sets with the tasks they assigned. By doing so, principals indicated this would assist in the coach's confidence and overall success in the position. This was also important for principals because they knew the assigned tasks would get completed with fidelity. It also meant 
they would need to spend less time coaching and guiding. Given the busy nature of the role, several principals indicated they could assign these types of tasks to their academic instructional coach and know they would get cone in a timely manner without little interaction or questions from the coach. This role group often used this as a rationale for assigning tasks for coaches to complete. Oppositely, principals indicated they also knew the weaknesses of the coaches in the building and would attempt to divert certain tasks away from those skill sets. Principal P11 explains, "She's not a numbers gal so she doesn't do any of my numbers."

Second, principals supported coaches by hiring them in to the position knowing it was a stepping-stone to higher administrator positions such as an assistant principal. School leaders understand the importance of putting the right people in the right roles in that process. They also know that putting people in the right roles can assist in how they delegate work to school leaders. This is evidenced in Principal P1's statement: We've got a lot of different resource teachers within this building that want to be assistant principals and assistant principals that want to be principals and part of the Academy structure that we do, is that I'm what they call the executive principal and so I'm really supposed to oversee the entire school structure and so in doing that, I'm able to divvy out and delegate which I'm really fine doing because I put a lot of emphasis in who I hire and putting them in the roles where they have the most strength.

In this way, principals also indicated they were vested in the coach's aspirations and wanted to see the coaches achieve professional goals. One principal explained how promoting a teacher within the building would ultimately improve her school culture. 
She felt other teachers could potentially be empowered and realize their hard work could lead into other positions.

The third component of this theme was for principals to support academic instructional coaches by giving them tasks and assignments that would address specific growth areas or relate to a skill set needed for a higher position in administration. While this is different than matching individual skill sets with tasks, principals indicated they also used this strategy knowing it would assist the coach in a later role (i.e., assistant principal). In this area, the primary focus was on working to get coaches to work with other teachers and providing support through existing administrators. Specifically, this meant including the academic instructional coaches in administration meetings and activities typically delegated to administrators.

\section{Mentorship According to Academic Instructional Coaches}

Two major themes were presented in the academic instructional coach data. Academic instructional coaches did not indicate any formal or informal systems for mentorship. Rather, most academic instructional coaches indicated they perceived a sense of autonomy and freedom from micromanagement in their assignments from the

principal. Academic instructional coaches also explained a majority of their growth and mentorship arose from developing relationships with other administrators or coaches in the district (Table 4).

Diving deeper into the first theme, academic instructional coaches not did not mention any clear processes for mentoring from principals. In reality, only one coach explicitly mentioned an informal structure for feedback. Therefore, coaches did not fully recognize their informal interactions with principals, explained by principals above, as 
opportunities for mentoring. Instead, academic instructional coaches interpreted the lack of formal meeting structures, job expectations, and feedback systems as an opportunity for conducting the coaching work as they saw fit. Four coaches communicated a high level of autonomy, and one coach seemed to appreciate the level of autonomy given as they completed work related tasks. For them, this was one way the principal was expressing trust and confidence in their work. Academic instructional coach G12 explained, "I can just go and vent and have someone listen to me for five minutes. That's probably the most single useful thing besides my boss understanding that my style is not one you can micro-manage and keep me happy."

Interestingly, evidence of an understanding of expectations was apparent with academic instructional coaches even though informal feedback structures was not mentioned. In half of the coaches interviewed, coaches knew what their supervisors expected but did not indicate a formal structure for this process. Another coach, also was clear on her role and duty within the school given she received no formal or informal communication with the principal. This would indicate some level of communication around expectations informally and corroborate the principal's claims of providing significant feedback informally.

Table 4. Principal's mentoring practices themes and codes

\begin{tabular}{llcccccc}
\hline & \multicolumn{1}{c}{ Academic instructional coach Participant } \\
Theme & Code & G7 & G8 & G11 & G12 & G14 & G15 \\
\hline \multirow{2}{*}{$\begin{array}{l}\text { Lack of } \\
\text { Formal/Informal }\end{array}$} & Autonomy & & & $\mathrm{X}$ & $\mathrm{X}$ & $\mathrm{X}$ & $\mathrm{X}$ \\
Process & $\begin{array}{l}\text { Clear expectation } \\
\text { process }\end{array}$ & $\mathrm{X}$ & & & & & \\
& Laissez Faire & $\mathrm{X}$ & & & $\mathrm{X}$ & $\mathrm{X}$ & $\mathrm{X}$ \\
\hline $\begin{array}{l}\text { Relationships } \\
\text { with } \text { other } \\
\text { administrators }\end{array}$ & $\begin{array}{l}\text { Support from peer } \\
\text { Support from }\end{array}$ & $\mathrm{X}$ & & $\mathrm{X}$ & $\mathrm{X}$ & $\mathrm{X}$ & $\mathrm{X}$ \\
administrator & $\mathrm{X}$ & $\mathrm{X}$ & $\mathrm{X}$ & & $\mathrm{X}$ & \\
\hline
\end{tabular}

Notes: "X" represents the coach's coded initial response 
This was not the case in all situations. One particular coach indicated she didn't have a clear picture of her principal's expectations and that these had never been formally communicated. Academic instructional coach G15 explicated, "I've had a very supportive principal here. However, I didn't get a lot of job description when I came.” Later in the interview, she reiterated:

I'm lucky that [G14] was here too because I could work with her and sort of set some things up that I wanted to do, but it was pretty much left to my own devices as far as like where I could be most helpful.

At this same particular school, there seems to be a difference between the way academic instructional coaches and principals perceive mentorship. While principals feel they spend significant amount of time coaching and giving feedback informally, academic instructional coaches do not perceive this as clear direction or guidance for their work. This is most clear in the contrasting narratives presented by Principal P14 and another academic instructional coach. Principal P14 states, "We'll do like every other week. We would have check in with them, like we would have an instructional support team meeting with my coaches.” Oppositely, academic instructional coach G14 stated: I guess I don't really know. I've never had a conversation with P14 to talk about what it is he specifically would like done. I guess the things that I've done in the past, I must do well enough so it just kind of keeps continuing.

All of this is not to say that academic instructional coaches did not mention accessibility to principals or that they were not able to gain information from their supervisor throughout the year. Academic instructional coaches did indicate they were able to meet or consult with the principal frequently on issues they were experiencing. It 
is also important to highlight most coaches had a general satisfaction with their existent interactions with the principal and level of support. The message from coaches was that these were simply opportunities to get feedback or answer questions on a particular task, not feedback or support on overall growth and development. For this, academic instructional coaches looked elsewhere.

While two academic instructional coaches did mention, they sought their building leader for role clarity or expectation guidance, most sought other sources for growth and development. This was the second major theme that emerged from the academic instructional coach data. Six of 6 coaches explained they sought guidance from others in the building, rather than their principal. During the interviews, three principals also acknowledged their academic instructional coach sought additional guidance from others in the building. Six academic instructional coaches explained that they would typically rely on other academic instructional coaches in their building, other academic instructional coaches in the district, or an assistant principal. When collaborating with peers in the academic instructional coach role, coaches often used this person to get feedback on a task, ask for assistance in how to coach a teacher, or for general guidance on how to proceed with work related tasks.

When seeking support from assistant principals, coaches alluded to some of the same situations above, however, some noted the importance of getting a teachers evaluator involved in coaching a teacher. Ultimately, this was designed to get some buyin from the teacher being coached, and not all of the instances of assistant principal involvement occurred for this reason. For example, coach G14 outlines how she collaborates with assistant principals: 
I think because I have KTIP [new teacher internship] with Ms. Cardell [assistant principal] and Mr. Jay [assistant principal], if I see something in a classroom, it's very easy for me to go and talk to them about it. You know, about teachers on their floors. Mr. Motley [assistant principal] and I have a pretty good relationship. We're doing NISSLE together so it's easy for me to go in and ask him questions. They [assistant principals] ask me questions which has been them getting more clarification from me about certain things too. So, having the relationship with them is good...to be able to say, okay, this is what I'm seeing and when you are doing the evaluation it may be something you want to look at.

Coach G8 further highlights the significance of principal support by saying, "If I don't have principal support then I'm no good. I have felt that before the current principal."

Oppositely, there was one academic instructional coach who sought direct feedback from the principal of the school. In this particular situation, the coach explained that she was the lead coach. She was the coach other academic instructional coaches relied on for support, as she was the most veteran. As a result of this dynamic, the lead coach often relied on the direct support of the principal. She explains, "But he's been really busy this year so when I really need help, [P11] is usually my go-to because I'm the most senior of the coaches."

Most academic instructional coaches sought support on their own accord. While the academic instructional coaches were a part of role group teams within the building organized by the principal, most of the time, academic instructional coaches relied on one particular person with whom they sought on their own time. There was no evidence of any formal mentorships or collaborative teams specifically designed by the principal to 
foster this relationship, and the relationships arose out of a need for support. The idea of relational mentoring is most clearly discussed by academic instructional coach G8:

A lot of my peer group are administrators - principals, assistant principals. If we're ever talking about the context or if there's an issue with how to coach somebody or there's an issue about how to deliver this professional development, something of that sort, what are your thoughts on a PLC topic, it's probably more due to the relationships I have with them, rather than that they are in an administrative role.

In this particular situation, participant G8 outlines some of the role groups she seeks, and that she solely seeks the particular person in the role groups because of her relationship with that peer. It is also important to note that all schools in the study, as a result of being AIS, had additional coaches in the building for which coaches could seek support.

However, in four schools, these additional positions were not mentioned as a resource for support. Coaches had to rely on others, not currently in the role for guidance, feedback, and direction. Additionally, some even indicated looking to their peers for overall guidance on what a typical day should entail. Participant G14 indicates, “...just now working with the other GCCs [Goal Clarity Coaches] in other buildings to come up with a somewhat of a normal day for a GCC."

\section{Cross-Case Analysis: The Development of Mentorship According to both Academic Instructional Coaches and Principals}

There were, however, some key factors both principals and academic instructional coaches believed contributed to coach development. For both groups, this included building relationships and ensuring academic instructional coaches felt supported in their roles. When it comes to relationships, coaches and principals expressed the importance 
of building and having trust, maintaining honesty and transparency, and connecting with one another personally. Developing from these relationships, participants in both roles understood and actively took steps to ensure academic instructional coaches were supported in the decisions and actions they took in the roles.

In one form or another, principals and coaches discussed relationship building 32 times throughout the interview process. In both roles, relationships were the key ingredient in building and developing coaches. In all but one instance, discussed momentarily, coaches and principals communicated they had each developed close relationships with the coaches. Often these relationships transcended into each participant's personal life. Trust, honesty and transparency, and personal openness were the key factors in developing relationships.

Trust was mentioned numerous times as a key ingredient to the mentoring relationship amongst participants, and was referenced in variety of ways. In some cases, participants identified trust as a necessary component for completing tasks. Principals indicated they need to have trust in the coach to complete tasks. This meant ensuring reports were conducted within timelines and with substantial fidelity. It also meant an opportunity for coaches to take tasks off their plate. By simply trusting coaches to conduct assigned tasks, they were free to tackle other issues and projects. Principal P3 explained this idea most thoroughly when referring to a professional development meeting:

She totally planned the agenda. We just talked about it. She can take what we discuss, my vision and create and design and put together an agenda and a workshop of things together. I just have a lot of trust in her to do that. 
Coaches perceived these opportunities to complete tasks and projects with little oversight positively. For them, it was important their supervisors trusted them to complete these tasks with little oversight or review, and ultimately, were able to develop confidence in their role. Academic instructional coach G12 highlights her pride when she states:

Well, one of the opportunities that I've had, that I'm absolutely thrilled with is the fact that P12, my principal, he may not talk to me, he might say hi, but he might not check on me for weeks at a time if I don't go in and say, “hey you need something?” He knows that he can give me the work and it will be done the way he wants it. If I'm not sure, I can ask. He never has to worry.

The development of trust was also significant for principals and coaches for other reasons. It was important for coaches and principals to be able to confide in one another. As principals navigate what they perceived as toxic school cultures and personal issues with students and teachers, they want to know they can trust coaches with confidential information. In this way, trust was also considered a barrier from some principals. For Principal P10, a lack of trust with her coach created a gap in the relationship building process that impeded her ability to support and develop her coach. She explained: We take two steps forward and three steps backward in the trust area, in the professionalism area, [and] in the confidentiality area. But, when I ask her to do something, she does, and she knows how to do it very well. I continue to try to help her grow professionally and I'm very up front with her about those areas of growth for her. 
Coaches also understand the importance of this, but from a different perspective. Coaches rely on principal trust when they are seeking support in growth areas or lack the knowledge or skills needed for completing tasks.

Relationships and trust were also bolstered by principal's willingness to be honest and transparent with coaches. This honesty and transparency took form in a variety of ways. For coaches receiving feedback, it was important for principals to be up front and direct with the specific issues they were having with coaches. Further, coaches expressed appreciation for opportunities to give principals feedback. In two particular situations, coaches discussed their ability to approach their principal with an issue of disgust or disagreement. Both coaches indicated the principal would often consider the feedback and adjust the approach. Principals also highlighted the importance of getting critical feedback from the coaches. As a result of the relationship, principals could accept feedback from coaches, even when it was not positive. Transparency in communication between coaches and principals was also a way for principals to keep a touch on the informal culture of the school. Principal P4 relied on some of this informal feedback to gauge the progression of her school. She explains the following:

So, I mean trust is the number one element is building a relationship built on trust where you know she can come into my office and be like [P4], Rome is burning. I count on her for that. I don't need anybody to be my yes person.

Most notably, principals and coaches discussed the importance of knowing one another personally as a way to foster and build relationships. Personal relationships were fostered in a variety of ways. In one context, led by Principal P11, the school's leader routinely shared personal information about challenging life experiences with her staff. 
From the coach's perspective, this sent the message her principal would be able to support her through anything, personal or professional. Principal P14 expressed a similar approach to mentorship with his coaches. In his work, he explains he takes the time to foster relationships with his staff as a way of communicating their importance to the school's work. Further, he highlights his previous mentors, with whom he respected, spent time getting to know him.

Two principals emphasized the importance of building a relationship over time. Principal P12 and P14 both understood the relationship with their coach as a result of work history. In each case, the principals had previously worked with the coach in another role or setting. For these individuals, their relationships spawned from numerous work collaboration over spans lasting longer than five years.

Other principals and coaches described relationship building by spending time with one another outside the work context. One principal emphasized the importance of including the coach in social events with school staff. This opportunity provided the coach some time to separate themselves from other role groups and interact with administrators in a different way. The principals share the following ways she includes her coach in other aspects of her life:

You know, I mean, we've hung out outside of school, that kind of thing. I think that's important for her because if I don't include her that way, then she hangs with the teachers and not that there always has to be a division but that can create some uncomfortable situations for her. There is a line there. She learned that early. So early in the school year, she went out with some teachers and she came back to school the next day and said I'm never doing that again. She said, it's just different now, it's just different. 
Interestingly, the principal explains her emphasis on helping the coach understand the difference in teaching and more administrative roles. It appears the coach was also using the principal as a confidant in this way.

Feeling of support was the second major theme both principals and coaches expressed interest as an integral part of coach development. Principals explained that it was important for coaches to feel supported by the administration and coaches reported a general sense of confidence surrounding a leader's perceived support. For coaches, support took shape in a couple of ways. Coaches who felt supported explained they needed the principal support to accomplish tasks. If they did not have the principals backing with a teacher, it was extremely difficult to do their job. When this support did not occur, coaches sensed a lack of relevance and credibility amongst the teacher staff with which they were trying to assist. Academic instructional coach G8 emphasized the principal's support as legitimacy to her work. She explained, "If I don't have principal support then I'm no good. I have felt that before the current principal. Like I said, I'm in that quasi role of trying to create change without the authority to mandate any change." In this situation, it is notable the academic instructional coach also refers to her role as quasi-administrative. In other words, the coach does not evaluate any of the teachers with whom she is providing support. For this reason, the coach further indicated it is difficult to get teachers to act if they do not think you can do anything to them. Coaches also expressed support in another way. Coach G15 stated, "If I come up with an idea and bring it to him and thinks it's a good idea, he will help me with whatever resources and time I need to do that." For this coach, support was the ability of her principal to provide the training and resources she needed to complete her duties. Three principals also view 
support in this way. As a principal, participants expressed a desire to make sure the staff in their building had the resources necessary to be effective in their roles. This included equipping academic instructional coaches with the professional development and resources necessary. Principal P10 highlighted this by saying:

I think that was that was great for her. If there's ever any professional development that she wants to go to or that I see that she needs to attend, then I will send her. I was asked to be part of this whole new redesign of our professional development system and I took her with me because she's really good at that.

Another principal outlined her support by ensuring the academic instructional coach was able to focus on the tasks that had been assigned. It appears there are certain situations where other school administrators, who may evaluate the academic instructional coach, may ask for other types of assistance from the academic instructional coach. In the school below, the academic instructional coach we being asked to chaperone school events by an administrator outside of the principal. In this case, it was important for the principal to support the coach by providing clear role clarity to others in the building. She highlights this by saying:

There have been times when she would say there's this I'm being asked to chaperone and I would tell her anything that anybody asks you that is outside of these lanes, I want to know. So, she would sometimes say, I'm being asked to chaperone the biology field trip, they need ten more adults and is it okay so I would say what's on your calendar that day. In this situation, the coach is specifically asking the principal for support in dealing with other administrators. 
In sum, the informant data relating to research question number one is informative. First, the data explain there are drastic differences between the ways principals and coaches view mentorship. Principals view informal feedback, and staff development as an integral component to supporting academic instructional coaches. Principals view frequent, on-the-fly, interactions with coaches to be vital to their development. They use these opportunities, typically arising out of a district directive, school issue, or deadline, to work with the coach to provide feedback, role clarity, and deliver expectations. Principals also strategically place academic instructional coaches into this role and assign tasks that both align to a coach's skillset and support their growth. In many cases, this is done intentionally as a way of developing coaches for success in higher administrative roles.

What is most striking about the academic instructional coaching data are that coaches do not perceive any real system or clear support for development in their building. They do not mention informal feedback, as discussed by principals, as an integral component of their development. Further, academic instructional coaches often seek guidance from others in their building or district. Depending on each coach's context, this includes guidance from a variety of roles in the building, many different from their own. It also it is a self-seeking process. Academic instructional coaches seek these peers for support only when they have issues or need additional guidance.

Second, there are also ways in which both principals and coaches view coach development via mentorship. The idea of the development of relationships between coaches and principals is evidenced as one of the main sources of mentorship for principals and coaches. In fact, this topic was discussed most often by all participants 
during the data collection process. Relationships function in a variety of ways depending on the context, but ultimately serve to develop trust, accountability, and personal friendships. For principals and coaches, this allows for rich opportunities to engage one another, be truthful about concerns, and support one another in their respective roles.

Relationships also seem to support coaches and principals emphasizing the important of supporting one another in their roles. Feelings of support were essential in carrying out the duties of the academic instructional coach role. It was imperative for principals to feel they were engaging coaches by making sure they were able to attend relevant trainings and receive resources. It was also important for coaches to get support from principals when they were asked to perform duties outside their traditional roles. In these cases, coaches relied to principals to clearly communicate coach role expectations to other administrators in the building who may be asking coaches to perform unassigned tasks, such as monitor a field trip.

\section{The Provision of Mentoring Supports and their Perceptions of Benefits}

The second research question aimed to understand the specific ways academic instructional coaches are supported and the participants' perceptions of benefits therein. What follows are findings on: 1.) the supports principals identify as beneficial to coach development; 2.) the supports coaches perceive as beneficial to coach development, and 3.) a cross-case analysis, summarizing the codes and themes that emerged from both principals and coaches in terms of ideal supports for development.

\section{Mentoring Supports and their Perceptions of Benefits according to Principals}

For principals, removing barriers is a key component of coach development, and two of the biggest barriers to coach development are time and role clarity. Principals 
believe coaches need more time to conduct the work and clarity on the role of the coach in the building. These ideas represented the two major themes emerging from the data on coach development.

The theme of additional time manifested in several different ways, and in sum, five principals explicitly mentioned time as a main barrier to coach development. One principal indicated the coach needed extended time in the form of additional work days. Principal P7 stated;

I would like her to work more days because just like yesterday, I had to text her about stuff that she's very much a part of. So, it would be nice if she was on the same schedule as the Academy Coach. They still get that month off basically but they work late you know. They work longer. They come back sooner because it just makes it hard when she's obviously a major part of our retreat planning and so she's going to do a lot of that when she's not on the clock.

In this excerpt, the principal indicates that the she must call on the coach to do work when the coach is not contractually working (i.e. summer). This is supported by another principal who thought it would be beneficial for coaches to work more during the summer months to support planning for the upcoming school year.

For other principals, time throughout the day to conduct "coaching" work was limited. This was informed by principals who believed it was impossible for one coach to support all staff members. Principal P14 states, "I think one of the challenges with a coach position is having the ability to reach everybody, especially in a building this size and with different content expertise and things like that." To combat this issue of time, 
the same principal hired additional coaches who could support school goals. He goes on to say:

Who were seeking, and hired additional coaches, due to the need for this role to further support school goals. I couldn't see us making the progress we've made with just one GCC. I think a lot of it has been because we've had not only our two GCCS, but also our teacher in residence, and a solid KDE team.

According to principals, there was another component critical to coach development. Role clarity was mentioned by six principals as a key way to develop and support coaches. Within this theme, principals continued to discuss the various ways coaches were used within their own building and across the district. Principals indicated it was hard to provide support for coaches when each coach was conducting different work within the school. Often, the work was completely different than the work done by coaches at other schools. For example, Principal P1 outlined the following:

I think the GCC position is so school-specific that you get into a way of this is how you think it's done. How I want it done, but there are others schools that do it different ways. There's other GCC coaches, other principals that utilize them in different ways, maybe not even in the state of Kentucky, maybe not even a GCC at all.

In other statements reinforcing this idea, principals indicated they placed and assigned coaches strategically based on coach skill sets. Principal P9 provides a brief summary of how this may manifest:

If they're looking to market their school in a different way, they may use a GCC to help to drive the school in that direction via social media. They have different strengths. Their aware of different things that are talked about. There are not real parameters on 
who to hire as a GCC that I'm aware of. The principal selection of a resource teacher just to fill this role so you know maybe some, maybe there's some nepotism in who is hired as a GGC or they had different skill sets, different requirements.

In sum, principals understand the best way to develop coaches is through the elimination of barriers. The current work structure for coaches limits their ability to work at times when principals could better use them. This would include holiday breaks and summer hours. Principals also indicated coaches need more time throughout the day to meet the needs of all teachers in the building. It is also important for coaches to have role clarity in their jobs. Principals indicated coaches were used in vastly different ways throughout the district, and this differentiation created a barrier of how to support coaches with varying needs.

\section{Mentoring Supports and their Perceptions of Benefits According to Coaches}

Coaches identified two main themes critical to development. These themes contrasted with principal's perceptions of coach development. First, coaches relied heavily on literature on coach development. Second, coaches felt they need more opportunities to focus on the work of coaching. These two themes are discussed in detail below.

In total, 4 of the 6 coaches mentioned print literature as a key component to growth. While numerous books were mentioned throughout the interviews, one book, The Art of Coaching (Aguilar, 2013), was mentioned three times as a valuable resource. In seeking these resources, coaches either sought this book out on their own or were provided the resource by the principal or district staff. In one particular case, a principal led a book study with her coach on this particular book. This was perceived as beneficial 
by the coach. At this particular site, the coach saw the principal as the leader of the professional development of the school and took it upon herself to support the individual needs of her staff, and particularly, this coach.

Coaches were also clear in identifying the specific barriers they faced as they approached the work. In this theme, coaches indicated a need for more opportunities to focus on coaching related work. Doing so, would assist in their overall development. Two coaches specifically spoke of being pulled back into classrooms as substitutes when there was a shortage of teachers on a particular day. When asked about barriers to coach development, coach G15 mentioned unrelated job tasks that can get in the way of the work. She indicated, "I definitely think doing things like subbing or working on mindless paperwork or organizational stuff." Another coach further highlighted this idea by recalling a time when she was only able to "coach" two days in one month. Coach G12 states:

Being pulled out. Having my time dictated to like I was in my office two days during the entire month of October this past year. I was at district PD [professional development] for half of it. What did I learn at that PD? Nothing! I could have given every one of the PDs but they were mandatory so I didn't have a choice. I had to go. So, for the month of October, being pulled out all of that, I couldn't get anything started.

These excerpts expose a key component to a coach's perceptions of benefits of particular supports. Coaches reported that they would feel more supported and developed if educational leaders would remove barriers to carrying out job-related tasks. Their perceptions are different from those of the principal informants' perceptions outlined 
previously. In this case, coaches are not asking for additional time. They are asking for time to simply do the work.

As mentioned, coaches relied heavily on literature related to coaching for development. Coaches also yearned for opportunities to focus specifically on the role of coaching. In other words, coaches were frustrated by the numerous duties, such as substituting, that got in the way of coaching work. Of equal significance, it is important to note all but one coach failed to mention any specific mentoring relationships with principals as a key to their development. This point, highlighted in the section below, was key for both principals and coaches.

\section{Cross-Case Analysis: The Provision of Mentoring Supports and their Perceptions of Benefits According to both Principals and Coaches}

In sum, there was a general dissatisfaction for the current ways coaches were being developed by both principals and coaches. The data analysis revealed two major themes relating to this topic (See Table 5). First, principals and coaches agree collaboration amongst peers is invaluable to coach development. Second, coaches and principals perceive existent professional development a barrier to coach growth. According to participants, coaches in the district had numerous opportunities to participate in professional development. Ultimately, the experiences around these trainings, conducted by individual schools, the district, and even third-party contractors significantly influenced coach's beliefs about their individual growth. Overall data in this area points to some major gaps in the availability of supports.

Most of all, coaches yearned for opportunities to collaborate with peers in similar roles. Specifically, coaches wanted protected time opportunities to discuss issues, ask 
questions, and outline roles in small group settings. This allowed coaches to ask the specific questions they had, rather than receive a uniform method or approach. They were more differentiated towards individual needs. In the past, coaches had been given limited access to these structured collaboration times, but thought them most beneficial. Within this same idea, one principal even mentioned an opportunity to establish formal mentorships with other coaches. Principal P7 elaborated, "Maybe it would have been nice to have a GCC [Goal Clarity Coach] mentor, or somebody telling me here are some great resources to set your coach up with." A more tangible view of this idea was outlined by Principal P1:

Why can't there be opportunities for those people to go different places, to see different things done, to collaborate more together, to come back with more ideas on how to best utilize their position to help students, to be the best for the students? That's what it comes down to.

These ideas are further supported by earlier claims from coaches indicating they often looked to peers, on their own accord, for guidance and support in the role.

It also important to highlight the discussion surrounding this question emphasized the identification of existing current barriers and frustrations related to professional development. This was the second theme that emerged from the data. Specifically, coaches and principals discussed an overall lack of professional development opportunities for academic instructional coaches. This included both a lack within the school and within the district. Some coaches discussed the majority of their trainings targeted a teacher audience rather than a coaching audience. This presented challenges in translating materials and skillsets to coaching. At the district level, while participants 
indicated training existed, most determined the training was insufficient. The trainings were considered insufficient because coaches conducted various roles within each school. In other words, the trainings were not conducive to differentiation, and, therefore, did not target individual growth needs. There were two principals who actually supported academic instructional coaches by telling them not to attend district level trainings. It is necessary to note, however, these trainings were typically mandated by district staff. Principal P11 stated, "So you know, we have sort of opted for her to not necessarily participate in anything at the district." Regardless, principals and coaches felt time was better spent working within the school. For these reasons, formal professional development was rarely mentioned as a specific strategy or support for academic instructional coaches.

In sum, there was a general dissatisfaction for the current ways coaches were being developed. This dissatisfaction arose from previous experience with district level trainings and a general lack of other available and relevant trainings. Most coaches continue to believe the most relevant guidance is that of peers, developed in a method conducive to their individual needs. 
Table 5. Provision of Mentoring Supports and their Perceptions of Benefits According to both Principals and Coaches

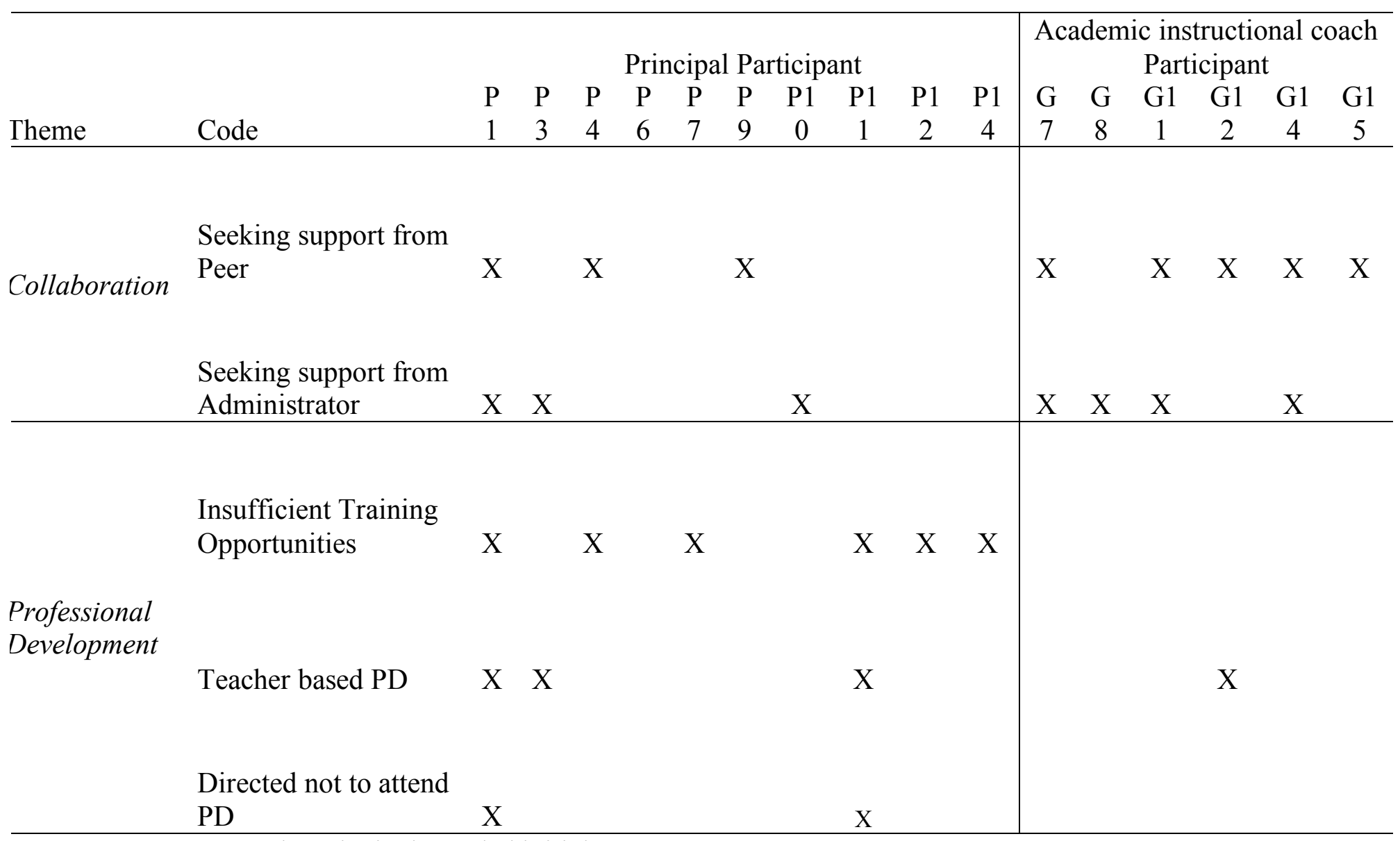

Notes: "X" represents the principal's coded initial response 


\section{Mentorship in the AIS context}

As mentioned previously, one key distinction in this study is the emphasis of academic instructional coach development in an AIS context. Research on this topic is elusive or non-existent. In analyzing data relevant to this type of context, several themes emerged. Relationships continue to be discussed by participants a meaningful aspect of mentorship. Principals and Coaches continued to emphasize this idea throughout the data collection process. Another key component of this work in an AIS context often involves the mentoring and coaching in environments where staff is frequently changing. Because of the countless reporting and documenting occurring in this context, it appears a majority of academic instructional coach tasks are the completion, creation, and analysis

of district and state level reporting. In this way, academic instructional coaches spend significant amount of time working to complete these types of reports. Much of the interaction between the principal and the coach centers on completing, analyzing, and reviewing necessary paperwork. Each of these three themes will be discussed in the following paragraphs.

Relationships continued to be emphasized when participants discussed working in an AIS context. As mentioned earlier, participants discussed the concept of relationships throughout the interviews. However, when asked about the AIS context, principals and coaches deliberated on the topic of relationships the most. In talking about relationships in the AIS context, participants mentioned the importance of having relationships as a means to get people to do what is asked. Academic instructional coach G8 outlines this idea: 
I keep going back to building relationships. Like I mentioned earlier, should be one of their priorities coming in to a new building, at least, and being aware of the perception that people may have as an outsider who's not in the classroom so it's like just being aware of that and navigating around that so teachers are still successful.

Other coaches explained that simply being in an AIS context forces one to build relationships with one another. Specifically, the coaches talk about the stress and exhaustion of working through audits, school re-staffing, and day to day operations. Going through this with someone else creates a bond. Coach G11 provides evidence of this by stating, "So, that was kind of stressful. When you live through that kind of thing, you kind of have a bond so that original group of instructional leaders." She goes on to state, "We went through a lot when we had to restructure and we were the only middle school actually — probably the only school that restructured where we - everybody had to reapply."

Another key component of working in an AIS context is dealing with staff issues. Explicitly, participants indicated that working in an AIS context meant constantly training new staff and working with a generally younger staff population. The participants indicated working with new or ever-changing staff was difficult for several reasons. One coach explains:

The needs are going to differ between a veteran teacher and a new teacher because I think back to like having a PD and it is just a teacher asked a question like yeah do this and this and this so for me it's like $\mathrm{ABC}$ to do those. But to them it's like, you just asked me to move mountains. Lady, are you crazy? So, then it's like I picked up on her bodily gestures, you know, the nonverbal cues. Oh, I thought wait a minute. I take that back. 
Maybe if you start here with a small group of kids, let's pilot this with one class, you make it sound more manageable because I saw her, like her eyes got big. I think that AIS School new teacher support coach needs to make sure you are cognizant of the differentiation of teacher needs.

Another principal, $\mathrm{P} 4$, expressed frustration out of the constant rebuilding seemingly occurring year after year:

So, you have to be able to retain your people but working in an AIS school is really, really hard because every year it feels like you're starting at the bottom of the hill and you're having to push so that you get to the end of the year and you feel like you're halfway there or two thirds the way up the hill. Then the new year starts and you feel like you're at the bottom of the hill again. So that you're always pushing or it feels like you're always pushing up against the rock going up stream and so for the coach and for all of us, it's that whole systems of supports for our teachers and being able to intuitively know what somebody's going to need and being able to have those relationships where it doesn't even have to be spoken anymore.

She goes on, once again, to emphasize the importance of relationships in this context. In this situation, relationships are used as a support mechanism for dealing with these staff challenges.

Lastly, when principals and coaches are collaborating in an AIS context, a large amount of time is dedicated to completing mandated tasks required from entities outside the school. This includes progress reports, data reports, and support plans required to be completed, tracked, and submitted to the district and the state. Many of these reports are akin only to the AIS context as a result of the specific grant funding these school receive. 
Therefore, most coaches and principals spend more time assigning or attempting to complete these tasks. According to the participants, particularly principals, this is not typical of other schools.

From the data analysis, several key points emerged. First, principals and coaches have similar and dissimilar views on mentoring. Principals believe coaches are developed through informal feedback and strategic hiring and assigning of tasks to coaches. On the contrary, coach data revealed an overall lack of information relating to their development. Most coaches, in fact, believed they were left to their own devices for development. They expressed autonomy. This led many coaches to seek guidance from other personnel in the school. Both coaches and principals believed relationships were an integral part of coach development. Both role groups also indicated these relationships led to feelings of support. Feeling supported in the role, therefore, was an important factor for coach development. When coaches and principals were asked the most beneficial ways to grow, they emphasized opportunities to collaborate amongst peer groups, and formal professional development was rarely mentioned as a valuable resource. Context was examined throughout this analysis. Specifically, how are coaches mentored and developed in the AIS context. Again, the data pointed to relationships. In some ways AIS contexts were responsible for creating these relationships. Other challenges presented by participants in this context included navigating staff retention issues and the constant demands of accountability via state and district reporting. An indepth discussion of this analysis follows. 


\section{CHAPTER V: DISCUSSION AND IMPLICATIONS}

This research study sought to improve understanding of how principals and academic instructional coaches perceived the development and mentorship of academic instructional coaches in an AIS school context and what mentoring supports academic instructional coaches perceive as beneficial to their development. Previous research in this area highlighted existing gaps around determining how academic instructional coaches are developed. Researchers also indicated a general lack of formalized training and support for academic instructional coaches in schools, calling for more research into how coaches were mentored and developed.

Like others (Deussen, 2007; Stock \& Duncan, 2010), this research study revealed a lack of formal support systems in the mentoring and development of academic instructional coaches. Academic instructional coaches maintain that they do not receive adequate training that they perceive as needed. This is in alignment with prior research (Blamey et al., 2008; Deussen, 2007; Stock \& Duncan, 2010). Existing training does not suffice as a result of irrelevance or lack of differentiation between opportunities offered for teacher and coaches, a finding consistent with the work of other researchers (Blamey et al., 2008). Coaches also failed to mention any type of formal processes for accessing feedback from their supervisor. As a result of this, coaches do not currently receive any type of formal development. In most cases, coaches are left to their own devices in their development, a finding that is also consistent with prior research (Gibson, 2005). This 
leads most coaches to seek support from other staff members in the building or district. Specifically, coaches in this study sought guidance from other academic instructional coaches throughout the district or school level administrators, typically assistant principals. When these interactions occurred, it typically resulted from the coach having to navigate a challenging situation. An example of this would be needing the support of an evaluating administrator to get a teacher to follow a directive from a coach. Again, the structure for these interactions were informal. The coach was able to self-determine the staff member with whom he or she reached to for support. The sporadic nature of these interactions led to varying frequencies in the overall support coaches received. Lastly, it is important to note coaches did not perceive the lack of supports as frustrating. For them, it appeared to come with the territory. Coaches understood the demands of a school-level principal and, in most cases, continued to think highly of their school's leadership. In actuality, most frustrations in training occurred when coaches were forced to attend district level training sessions. Coaches became frustrated, as they felt these trainings were irrelevant and/or did not cater to each individual's needs.

Coaches that served as informants in this study reported valuing and needing role clarity. Varying coach roles across the district's schools made it challenging to effectively support coaches in their work. Further, these differences across schools negatively affected the coaches' ability to seek support from peers. While coaches did indicate they had opportunities to collaborate and garner support from one another, it was challenging for them to seek common ground in collaboration and discussion. Similar issues are seen in current research. Coaches, operating in vastly different contexts, struggle to identify holistic and specific job duties that would assist in providing more 
targeted and streamlined supports to coaches (Denton \& Hasbrouck, 2009; Rush \& Young, 2011; Stock \& Duncan, 2010; Walpole \& Blamey, 2008).

This research study also presented an opportunity to better understand the ways coaches felt they could be developed more effectively. The coaches and principals that served as the informants for this study longed for opportunities to collaborate with peers. Like others (Marsh, McCombs, Mortelli, 2012) it was revealed that as coaches and principals continued to navigate their roles, it became clear that both principals and coaches desired training and support systems that would allow coaches to interact with their peers. Principals suggested coaches should be provided specific times throughout the year to collaborate, brainstorm, and ask questions related to their roles. This is also evidenced in the research. Accordingly, coaches consistently seek opportunities from peer and other administrative role groups for support (Marsh, McCombs, Mortelli, 2012).

Related to this idea of development, principals should be mindful of structuring feedback opportunities for coaches. Without a doubt, principals perceived their informal feedback structures pivotal for coach development. Alternatively, coaches never mentioned this as a manner for feedback. The data suggest coaches internalized much of this, on-the-fly, informal feedback as an opportunity for autonomy rather than direction. For some coaches, this led to misguided feelings and assumptions about their roles in the buildings. Others appreciated the ability to complete tasks as they see fit. This view is different than current literature. Previous research, as outlined above, clearly indicates coaches do not appreciate a lack of role clarity or opportunities for feedback (Blamey et al., 2008; Deussen, 2007; Stock \& Duncan, 2010). 
Relationships are key to a coach's development. For both principals and coaches, relationships transcended all areas of coach development. Relationships in this context served a variety of functions. Previous research of mentoring supports the above findings (Cook, 2012; Halai, 2006; Saffold, 2006; Shulman, 2007). Relationship building is a key component of mentoring and provide the foundation for support and development (Cook, 2012).

In collaborating with one another, relationships served as opportunities to seek support and growth on a personal level. This includes spending quality personal time with the principals and coaches. It also means sharing personal struggles and experiences with one another. Some of these personal struggles and experiences were connected to an individual's work in an AIS context. Going through re-staffing and state audits created a sense of belonging amongst principals and coaches alike. These relationships fostered trust, transparency, and honesty among each individual. These feelings of trust, transparency, and honesty allowed coaches and principals to move the work forward. Because of relationships, coaches and principals were honest in their openness about feedback for school programs, academic instructional coach skills, and expectations for one another.

These relationships also fostered an atmosphere of support. This idea is also in alignment with existing research. Mentoring creates feelings of support and success (Ehrich et al., 2004; Iancu-Haddad \& Oplatka, 2009). It was important for both coaches and principals to have each other's back. These feelings of support were manifested in several ways. Principals specifically placed coaches into roles and assigned tasks that ensured they would be successful. Principals also spent time and money to make sure 
coaches had what they needed in terms of resources. If coaches were interested in a particular professional development, principals would make sure they could attend. If a certain program or resource piqued interest for a coach, principals, if in agreement, would take steps to get the coach access to the resource. For coaches, feeling supported meant knowing the principal would support them in making decisions and completing role related tasks. Coaches wanted to know they could count on principals to hold others accountable. They also felt empowered when principals would take their advice or support a previous decision when working with teachers and other administrators.

While the AIS context presents numerous challenges for principals and coaches alike, the environment offers some benefits also. As a result of operating in an AIS context, principals often had to delegate a significant number of "rubber stamp" activities to coaches. In most cases, coaches were assigned with completing quarterly reports, professional development, and school improvement plans and grants. In some ways, these tasks interfered with the true work of the coach. As the title of Academic instructional coach suggests, the primary role of these positions is to carry out the instructional goals of the school. While these goals can look different from school to school, they do not typically include the creation, review, or submission of accountability type reporting. The AIS context also presents additional challenges in the area of staffing. Coaches and principals agree the retraining of new teachers, the loss of veteran teachers, and overall turnover of staff present challenges in carrying out the role of the coach. In some cases, the participants in this study felt they could not gain traction, as they were continuing to battle these issues. This was a struggle for coaches, as they would have to continue to meet teachers where they were. Most importantly, it seems 
most of these frustrations are mitigated in the AIS context by relationships. The stress and work load of this environment creates an atmosphere of collegiality, team support, and friendship. Principals and coaches experience many AIS-related events (i.e., audits, re-staffing) together. These staff members then internalize moving through these events as a bonding experience. Again, the development of a relationship is fostered from the specific experiences of working in an AIS school.

\section{Implications for Policy}

Role clarity, time, and job assignment continue to be barriers that the principal and coach participants believe affect coach growth. The issue of role clarity, and the varying ways this role is utilized within the school district make it difficult for coaches to be supported in a consistent and meaningful way. Therefore, it is recommended that the district and state improve clarity on this role. This would include more detailed job descriptions, tighter specificity for how these coaches and principals can utilize grant funding, and more accountability and data analysis on how the role is being implemented at each school. Adhering to these steps could also eliminate some of the other barriers presented by coaches. This would include coach concerns around having to substitute and complete non-job-related tasks.

Connected to this idea, Kane and Rosenquist (2018) emphasize the role of the hiring manager in coach task assignment and role clarity. Specifically, policy around funding and hiring of coaches should emphasis and clearly outline who should manage instructional coaches. While coaches are often hired by both district and school administrators, those instructional coaches hired and managed by district staff are more likely to spend time supporting coaches in the classroom (Kane \& Rosenquist, 2018). 
Principal managed staff are more likely to direct coaches to a wide variety of roles and job tasks (Kane \& Rosenquist, 2018). Most of these tasks do not include directly supporting teachers, and further muddle the roles and duties of a coach (Kane \& Rosenquist). Understanding this idea as it relates to role clarity is pivotal for coach development. When academic instructional coaches are able to spend more of their time on one task, it is much easier to support and mentor the coach in that specific area. Further, as districts and states look to establish systematic supports for coach development, the establishment of mentorships and peer support is much more relevant. Coaches will likely be able to find value in these collaborations as they are more applicable to the tasks they work on each day. In strengthening this recommendation, policy should also encourage district hired coaches to be placed in one school location during a calendar year (Kane \& Rosenquist, 2018). This would allow for opportunities to development trust and build relationships with school staff. It would also continue to thwart competing initiatives and contexts that may further pull the coach from supporting teachers.

Given the current ways coaches are utilized in the sampled schools that served as the context of this study, coaches may also benefit from extended work days. This would include extending coaches working calendar during appropriate breaks. This would also include additional summer hours to prepare and implement tasks needing to be completed prior to the start of the school year. Additional days may also be needed during the Winter Break and on days other administrators, such as assistant principals, typically work. Not only would this allow coaches additional time to conduct job related tasks, it would also be a time for the coach to further deepen relationships with peers and 
administrators. These opportunities are typically much more infrequent when students and teachers are also in the building competing for coaches' attention and support. Related to this idea of additional work days, it may be important to loosen restrictions on how some grant funding is provided to districts. In the current state, grant funds are rarely afforded to provide additional time for staff to plan and implement grant funding. Allowing for additional options in this way may again foster additional opportunities to develop and support coaches. Regardless, additional funding to support this role is necessary. While these funds may be used to better support coach growth through professionally development, additional funds are needed to provide additional time for coaches to do the work.

Additional work opportunities and enhanced role clarity may also inadvertently work to retain new and effective teachers. If coaches have additional time to spend working with teachers, it is likely teachers will feel more supported and able to stay in the profession longer. Additional days would allow coaches to focus more on coaching during the school day. Administrative and extra duties could then be completed when teachers are not back in the building. Role clarity will also improve a coaches ability to remain "on-task" in supporting new teachers. If job descriptions and specific roles clearly outline coaching and supporting teachers, coaches will be able to spend more time and align their everyday routines to these practices.

\section{Implications for Practice}

There are several implications for principals, coaches, and district leaders to consider when supporting academic instructional coaches. Based on this study, principals should seek opportunities to provide feedback and develop relationships with 
individual coaches in their schools. This would include formal mentoring structures that provide opportunities to collaborate with peers and other administrators supporting coaches.

Ultimately, principals should work to formalize frequent and quality feedback structures for coaches within their building. Doing so would mitigate chance encounters and opportunities for coach development. In the longer term, it may be an opportunity for coaches to realize the specific ways they are developed also. Also notable, these formal feedback structures can operate outside the typical evaluation process for coaches. While principals and coaches scantly mentioned the formal evaluation process as a mode for feedback, no participant indicated the evaluation process as meaningful.

From a coaching development standpoint, a formal structure for mentoring would prevent coaches from seeking this support on their own. Ultimately, this would provide additional relevance and consistency across the role. It would also mean coaches would be able to learn new skills sets, skills sets involving the coaching of others, prior to having the experiences. In other words, current coach practice is reactive. Coaches experience a challenging situation and then seek someone for support and assistance. A clear structure for peer support, as described above, would be more proactive. Coaches could receive guidance in consistent areas of concern prior to having an issue. Thus, eliminating the issue completely. Evidence exists to support this implication (Hudson; 2009, Washburn-Moses; 2010). This evidence recommends formal structures for mentoring as a means of supporting staff development. Further, clearly outlined mentoring programs have the ability to improve coach retention and overall job satisfaction (Saffold, 2006; Shulman, 2007). 
Clearly, relationships have meaningful implications for principals mentoring academic instructional coaches (Ehrich et al., 2004; Iancu-Haddad \& Oplatka, 2009; Kane and Rosenquist, 2018; Kram, 1985). It appears principals can take several steps to ensure the development of relationships with coaches. First, take time to get to know the coach. This includes both their personal experience, interests, and time outside of work. It also means getting to know their skill set. This will allow the principal an opportunity to assign tasks in which the coach can gain confidence and a sense of worth. Related to this, principals should know the aspirations of a coach and begin to assign tasks preparing them for those roles. Second, coaches and principals should be honest and transparent with one another. Doing so allows for opportunities to build trust. Honest criticism should also work both ways. Coaches and principals should allow to hear feedback from one another. Doing so will allow both groups to get a common understanding of the issues currently existent in the building. It is a way of gaining useful information to support the goals of the school. Third, principals should also provide opportunities to show coaches support. In other words, listen to the coach when he or she presents and issue. Provide the coach space and an opportunity to share their concerns and identify ways they would fix the issue. Support them by communicating shared expectations with other individuals who interact with the coach. Ultimately, these strategies will work to strengthen the overall relationship between the coach and principal. In turn, coaches will feel both affirmed and supported (Ehrich et al., 2004; Iancu-Haddad \& Oplatka, 2009; Kram, 1883). Coaches will also have the opportunity to support teacher retention. If principals model and emphasize relationships with the coach, this will likely transcend to 
other areas of the school, including classroom teachers. Relationship building in this area could also improve the coaches ability to support and retain teachers.

\section{Implications for Future Research}

The data and analysis presented in this study provides two opportunities for promising future research. First, the data suggest academic instructional coaches may be seeking other role groups for mentorships. This would include stakeholders such as assistant principal, peer academic instructional coaches, or other administrators in a building. In future, researchers may seek to explore the impact of these other role groups on academic instructional coach development. Second, as the limitation above suggests, as some participants opted out of participation in this study, there were few situations where the researcher was able to get an interview with the coach and the principal in the same school. Future research should aim to hone in on participants within the same building. Data from this type of study would strengthen current understanding. Such a study may also work to identify and flesh out the specific differences in how principals and coaches understand mentoring in their contexts.

A major limitation to this study that there were instances where the researcher was only able to interview one of the role groups in the school. For this particular study, there were more principal participants than academic instructional coach participants, and there were instances where the coach was unable to participate. Their voices were not always able to be a part of this research study. Therefore, it was difficult to verify and validate the individual viewpoint. There was not statements from others that would support or deny the individuals claim. In fact, from this study, two participants from the same school had differing viewpoints on certain topics and their interpretation of events. 
In an effort to strengthen data richness, future research in this area should work to ensure both the principal and the academic instructional coach were able to participate. 


\section{REFERENCES}

Ambrosetti, A. (2014). Are you ready to be a mentor? Preparing teachers for mentoring pre-service teachers. Australian Journal of Teacher Education, 39(6), 14.

Aguilar, E. (2013). Art of coaching: Effective strategies for school transformation. Jossey-Bass.

Augustine-Shaw, D., \& Funk, E. (2013). The influence of mentoring on developing leaders: Participants share their perspectives. Educational Considerations, 41(1), 1926.

Browne-Ferrigno, T. (2003). Becoming a principal: Role conception, initial socialization, role-identity transformation, purposeful engagement. Educational Administration Quarterly, 39(4), 468-503.

Browne-Ferrigno, T. (2007). Developing school leaders: Practitioner growth during an advanced leadership development program for principals and administrator-trained teachers. Journal of Research on Leadership Education, 2(3), 1-30.

Blamey, K. L., Meyer, C. K., \& Walpole, S. (2008). Middle and high school literacy coaches: A national survey. Journal of Adolescent \& Adult Literacy, 52(4), 310-323.

Center for Collaborative Education (2001). Promoting whole school reform: A closer look at the role of external facilitators. Center for Collaborative Education. 
Center for Collaborative Education (2002). The role of external facilitators in whole school reform: Teachers' perceptions of how coaches influence school change. Center for Collaborative Education.

Chao, G. T. (1992). Formal and informal mentorships: A comparison on mentoring functions and contrast with nonmentored counterparts. Personnel Psychology, 45(3), $619-636$.

Coggins, C. T., Stoddard, P. \& Culter, E. (2003). Improving instructional capacity through school-based reform coaches. The Annual Meeting of the American Educational Research Association, Chicago, IL.

Cook, J. (2012). Examining the mentoring experience of teachers. International Journal of Educational Leadership Preparation, 7(1), 10.

Copeland, S. M., \& Calhoun, D. W. (2014). Perceptions of mentoring: Examining the experiences of women superintendents. International Journal of Educational Leadership Preparation, 9(2), 28-46.

Creswell, J. W. (2012). Qualitative inquiry and research design: Choosing among five approaches. Sage.

Creswell, J. W. (2013). Research design: Qualitative, quantitative, and mixed methods approaches. Sage.

Crotty, M. (1998). The foundations of social research: Meaning and perspective in the research process. Sage.

Denton, C. A., \& Hasbrouck, J. (2009). A description of academic instructional coaching and its relationship to consultation. Journal of Educational \& Psychological Consultation, 19(2), 150-175. 
Deussen, T. (2007). Coach can mean many things: Five categories of literacy coaches in reading. Issues and Answers, 5(4), 1-31.

Ehrich, L. C., Hansford, B., \& Tennent, L. (2004). Formal mentoring programs in education and other professions: A review of the literature. Educational administration quarterly, 40(4), 518-540.

Eisenberg, E., \& Medrich, E. (2013). Make the case for coaching: Bolster support with evidence that coaching makes a difference. Journal of Staff Development, 34(5), 4849.

Fletcher, E. C. (2012). Business education university supervisors' perspectives of mentor teachers' competencies. Journal of Career and Technical Education, 27(1), 56-71.

Gallucci, C., Lare, M.V., Yoon, I., \& Boatright, B. (2010). Academic instructional coaching: Building theory about the role and organizational support for professional learning. American Education Research Journal, 47(4), 919-963.

Gibson, S. (2005). Developing knowledge of coaching. Issues in Teacher Education, $14(2), 63-74$.

Graves, S. M., Abbitt, J., Klett, M. D., \& Wang, C. (2009). A mentoring model for interactive online learning in support of a technology innovation challenge grant. Journal of Computing in Teacher Education, 26(1), 5-16.

Guinney, E. (2001). Coaching isn't just for athletes: The role of teacher leaders. Phi Delta Kappan, 82(10), 740-743.

Halai, A. (2006). Mentoring in-service teachers: Issues of role diversity. Teaching and Teacher Education, 22(6), 700-710. 
Hellsten, L.-a. M., Prytula, M. P., Ebanks, A., \& Lai, H. (2009). Teacher induction: Exploring beginning teacher mentorship. Canadian Journal of Education, 32(4), 703-733.

Hudson, P. (2010). Mentors report on their own mentoring practices. Australian Journal of Teacher Education, 35(7), 30-42.

Huguet, A., Marsh, J. A., \& Farrell, C. (2014). Building teachers' data-use capacity: Insights from strong and developing coaches. Education Policy Analysis Archives, $22(50), 1-31$.

Iancu-Haddad, D., \& Oplatka, I. (2009). Mentoring novice teachers: Motives, process, and outcomes from the mentor's point of view. New Educator, 5(1), 45-65.

Joyce, B. R., \& Showers, B. (1982). The coaching of teaching. Educational leadership, 40(1), 4-10.

Joyce, B. R., \& Showers, B. (1981). Transfer of training: the contribution of" coaching". Journal of Education, 163(2), 163-172.

Kane, B.D. \& Rosenquist, B. (2018). Making the most of instructional coaches. Phi Delta Kappan, 99(7), 21-25.

Kram, K. E. (1983). Phases of the mentor relationship. Academy of Management Journal, 26(4), 608-625.

Kram, K. E. (1985). Mentoring alternatives: The role of peer relationships in career development. Academy of management Journal, 28(1), 110-132.

Lee Hean, H. (2005). Love in mentoring. New Horizons in Education, 51(1), 106-110. 
Marsh, J. A. \& Farrell, C. (2015). How leaders can support teachers with data-driven decision making: A framework for understanding capacity building. Educational Management Administration and Leadership, 43(2) 269-289.

Marsh, J. A., McCombs, J. S., \& Martorell, F. (2012). Reading coach quality: Findings from Florida middle schools. Literacy Research and Instruction, 51(1), 1-26.

Miles, M. B., Huberman, A. M., \& Saldaña, J. (2013). Qualitative data analysis: A methods sourcebook. Sage.

Newstead, B., Saxton, A., \& Colby, S. J. (2008). Going for the gold: Secrets of successful schools. Education Next, 8(2), 38-45.

Normore, A. (2007). A continuum approach for developing school leaders in an urban district. Journal of Research on Leadership Education, 2(3), 45.

Onchwari, G., \& Keengwe, J. (2010). Teacher mentoring and early literacy learning: A case study of a mentor-coach initiative. Early Childhood Education Journal, 37(4), $311-317$

Ross, J. (1992). Teacher efficacy and the effects of coaching on student achievement. Canadian Journal of Education, 17(1), 51-65.

Rush, L. S., \& Young, S. (2011). Wyoming's instructional facilitator program: Teachers' beliefs about the impact of coaching on practice. Rural Educator, 32(2), 13-22.

Russell, M. L., \& Russell, J. A. (2011). Mentoring relationships: Cooperating teachers' perspectives on mentoring student interns. Professional Educator, 35(1), 21.

Saffold, F. (2006). Retaining urban teachers: The impact of mentoring. Journal of Urban Learning, Teaching, and Research, 2(1), 254-261.

Saldana, J. (2012). The coding manual for qualitative researchers. Sage. 
Shidler, L. (2009). The impact of time spent coaching for teacher efficacy on student achievement. Early Childhood Education Journal, 36(5), 453-460.

Showers, B. (1985). Teachers coaching teachers. Educational leadership,42(7), 43-48.

Shulman, J. H. (2004). From inspired vision to impossible dream: The dangers of imbalanced mentoring. Journal of Teacher Education, 55(5), 393-406.

Skedsmo, G., \& Huber, S. G. (2019). Forms and practices of accountability in education. Educational Assessment, Evaluation and Accountability, 31(3), 251-255.

Stanulis, R. N., \& Ames, K. T. (2009). Learning to mentor: Evidence and observation as tools in learning to teach. Professional Educator, 33(1), 11.

Stock, M. J., \& Duncan, H. E. (2010). Mentoring as a professional development strategy for academic instructional coaches: Who mentors the mentors? Planning and Changing, 41(1), 13.

Versland, T. M. (2013). Principal efficacy: Implications for rural "grow your own" leadership programs. Rural Educator, 35(1), 10.

Vygotsky, L. S. (1978). Mind in society: The development of higher psychological processes. Harvard University Press.

Walpole, S., \& Blamey, K. L. (2008). Elementary literacy coaches: The reality of dual roles. Reading Teacher, 62(3), 222-231.

Washburn-Moses, L. (2010). Rethinking mentoring: Comparing policy and practice in special and general education. Education Policy Analysis Archives, 18(32), 25.

Washington, C. E. (2007). Mentoring, organizational rank, and women's perceptions of advancement opportunities in the workplac,. Forum on Public Policy, Walden University, Ann Arbor. 
Wilson, P. F. (2001). Core virtues for the practice of mentoring. Journal of Psychology \& Theology, 29(2), 121.

Yin, R. (2014). Case Study Design and Research Methods. Sage. 


\section{APPENDIX A: INFORMED CONSENT}

\section{Subject Informed Consent Document}

Mentoring: A Case Study in the use of Mentorships in Academic instructional coach Development

Principal Investigator

Dr. Kyle Ingle

Department of Educational Leadership, Evaluation, and Organizational Development College of Education \& Human Development

University of Louisville

1905 South $1^{\text {st }}$

Street

Louisville, KY

40292

Co- Investigator

Matthew Anderson

Department of Educational Leadership, Evaluation, and Organizational Development

College of Education \& Human Development

University of Louisville

1905 South $1^{\text {st }}$

Street

Louisville, KY

40292

Site(s) where study is to be conducted:

County Public Schools

Phone number for subjects to call for questions:

Matthew Anderson 502-235-1173

\section{Introduction and Background Information}


You are invited to participate in a research study. The study is being conducted by Dr. Kyle Ingle, principal investigator, and Matthew Anderson of the University of Louisville Educational

Leadership, Evaluation, and Organizational Development Department. The study will take place at County Public School sites. Approximately 10-12 participants will be invited to participate.

\section{Purpose}

The purpose of this study is to better understand the role of mentorship and development of academic instructional coaches in a priority school in the era of accountability. Perceptions of current academic instructional coaches and principals will ideally help JCPS construct processes and structures to lay the foundation for development of academic instructional coaches within the district. Interview data will be used to better understand how academic instructional coaches are supported, developed, and mentored as they move from the classroom into coaching positions. Qualitative data gathered through interviews, field notes, and document analysis will be used to identify emerging patterns and converging themes. A criterion sample of 10-12 participants will be selected to help the researcher better understand this issue.

\section{Procedures}

Academic instructional coaches and principals will be asked to participate in one interview lasting no more than 60 minutes. Participants will be given the option to not answer any questions that may make them uncomfortable. Field notes will be utilized during the interviews. There is a possibility participants will be asked to participate in one follow up interview.

\section{Potential Risks}

There are risks associated with any interview. Those risk(s) is/are are minimal, and pertain to issues connected with the loss of confidentiality. Measures intended to limit potential risks have been addressed appropriately. There are no foreseeable risks, although there may be unforeseen risks.

\section{Benefits}

Benefits may include, but are not limited to:

- discovering new information pertaining to the challenges and opportunities associated with academic instructional coaching;

- highlighting the importance of sharing the experienced narratives of principals and academic instructional coaches who have worked diligently to improve school and student achievement 
- contributing to the small body of literature focused on the development of academic instructional coaches;

- $\quad$ providing the field of educational administration with key insights about the mentoring supports academic instructional coaches perceive as most beneficial to their development;

- emphasizing the need for the development of academic instructional coaching supports in the district.

\section{Compensation}

You will not be compensated for your time, inconvenience, or expenses while you are in this study.

\section{Confidentiality}

Total privacy cannot be guaranteed. Your privacy will be protected to the extent permitted by law. If the results from this study are published, your name will not be made public. While unlikely, the following may look at the study records:

- The University of Louisville Institutional Review Board, Human Subjects Protection Program Office

- Government agencies, such as: Office for Human Research Protection (OHRP)

All data will be stored on a password-protected computer and will be destroyed after the study is complete. Pseudonyms will also be used as identifiers throughout the study.

\section{Voluntary Participation}

Taking part in this study is voluntary. You may choose not to take part at all. If you decide to be in this study you may stop taking part at any time. If you decide not to be in this study or if you stop taking part at any time, you will not lose any benefits for which you may qualify.

\section{Research Subject's Rights, Questions, Concerns, and Complaints}

If you have any concerns or complaints about the study or the study staff, you have three options.

You may contact the principal investigator at 502-852-6097 and/or William.Ingle@louisville.edu.

You may contact the co-investigator at 502-235-1173 and/or matthew.anderson@jefferson.kyschools.us. 
If you have any questions about your rights as a study subject, questions, concerns or complaints, you may call the Human Subjects Protection Program Office (HSPPO) (502) 852-5188. You may discuss any questions about your rights as a subject, in secret, with a member of the Institutional Review Board (IRB) or the HSPPO staff. The IRB is an independent committee composed of members of the University community, staff of the institutions, as well as lay members of the community not connected with these institutions. The IRB has reviewed this study.

If you want to speak to a person outside the University, you may call 1-877-852-1167. You will be given the chance to talk about any questions, concerns or complaints in secret. This is a 24 hour hot line answered by people who do not work at the University of Louisville.

This paper tells you what will happen during the study if you choose to take part. Your signature means that this study has been discussed with you, that your questions have been answered, and that you will take part in the study. This informed consent document is not a contract. You are not giving up any legal rights by signing this informed consent document. You will be given a signed copy of this paper to keep for your records.

Signature of Subject/Legal Representative

Signature of Person Explaining the Consent Form

(if other than the Investigator)

Signature of Investigator

LIST OF INVESTIGATORS

Kyle Ingle (Principal Investigator)

Matthew Anderson
Date Signed

Date Signed

Date Signed

PHONE NUMBERS

502-852-6097

502-235-1173 


\section{APPENDIX B: INTERVIEW PROTOCOL (COACH)}

Interviewee Pseudonym:

Interviewer:

Date:

Location:

1. Describe your educational background.

2. How many years have you been in education?

3. How many years have you been an academic instructional coach?

4. How did you become a Goal Clarity Coach?

5. Describe your experience in working in a priority school context?

RQ1: How are academic instructional coaches developed and mentored in a priority school context?

1. Describe the transition from your previous role to the role of GCC.

2. How does your principal see your role? Is this different than how you see your role? If so, how?

3. Outline a typical day as a Goal Clarity Coach in your school. Is this different than your job description? If so, how?

4. What qualities are essential for someone in the GCC position in your school? How are these the same/different than a GCC working in a non-priority school?

5. Describe some challenges or opportunities you have experienced in this role.

a. How did you work through these challenges/opportunities (provide an example or scenario)?

6. Who supported you throughout the process? In what ways did they support you?

7. What is the nature of your typical interactions with your principal? What is your relationship with your principal? Would your principal be a source of knowledge/support/growth in working through the above? Why or Why not? 
8. How do you seek development/support/feedback from your principal?

9. Are there other people you look to for support in this role? Provide an example.

10. Why do you seek this person out, and how do they specifically support you?

11. How would you describe their role in your current development?

12. Describe any additional strategies you have employed or sought to grow professionally in your role as a GCC.

$\underline{\mathrm{RQ} 2:}$ What mentoring supports do academic instructional coaches perceive as beneficial to their development?

1. To what extent does mentoring, or your relationship with colleagues, play a factor in your professional development?

2. What did you see as valuable when learning from this individual (s)?

3. What are some other supports you perceive to be beneficial to your development as a coach?

4. What do you perceive to be detrimental to your overall development as a coach (barriers)?

5. What advice would you provide for someone in your role who is experiencing difficulty growing professionally in this role? 
APPENDIX C: INTERVIEW PROTOCOL (PRINCIPAL)

Interviewee Pseudonym:

Interviewer:

Date:

Location:

Describe your educational experience specific to the priority context.

How do you characterize your leadership practices/style?

RQ1: How are academic instructional coaches developed and mentored in a priority school context?

1. At your school, what need does the GCC fulfill? Describe how your GCC works to fill this need.

2. What qualities are essential for someone in the GCC position in your school? How are these the same/different than a GCC working in a priority school?

3. Has the GCC experienced any challenges/opportunities in your school? If so, provide examples.

a. How did the GCC work through this challenge/opportunity?

4. In what ways is the GCC supported in your building (PD, etc.)? Support or development?

5. With whom would you say the GCC looks to for support and why?

6. What role do you play in the development of the GCC?

a. What is your relationship with the GCC?

RQ 2: How are academic instructional coaches developed and mentored in a priority school context?

1. Describe some formal and informal ways you provide feedback and support to your coach?

a. Why do you choose this method?

2. What part of the support do you feel has been most beneficial? Why? 
3. If you had unlimited funds and resources, describe how you think your coach could best be supported? 


\section{CURRICULUM VITA}

NAME: $\quad$ Matthew Anderson

ADDRESS: 10632 Gleneagle Place

Louisville, KY 40223

DOB: $\quad$ Louisville, Kentucky - April 28, 1983

EDUCATION \& TRAINING:

Bachelor of Arts, Social Studies Education

Purdue University

2002-2004

Master of the Arts, Social Studies Education

University of Louisville

2006-2007

Specialist in Education, Educational Leadership

University of Louisville

2012-2015

Doctorate of Education, Educational Leadership

University of Louisville

2016-2021 